This document is confidential and is proprietary to the American Chemical Society and its authors. Do not copy or disclose without written permission. If you have received this item in error, notify the sender and delete all copies.

\title{
Bioinspired Aryldiazonium Carbohydrate Coatings: Reduced Adhesion of Foulants at Polymer and Stainless Steel Surfaces in a Marine Environment
}

\begin{tabular}{|r|l|}
\hline Journal: & ACS Sustainable Chemistry \& Engineering \\
\hline Manuscript ID & Sc-2017-03443p.R1 \\
\hline Manuscript Type: & Article \\
\hline Date Submitted by the Author: & n/a \\
\hline Complete List of Authors: & $\begin{array}{l}\text { Myles, Adam; Trinity College Dublin, School of Chemistry } \\
\text { Haberlin, Damien; University College Cork National University of Ireland, } \\
\text { Marine and Renewable Energy Centre, Environmental Research Centre } \\
\text { Esteban-Tejeda, Leticia; Trinity College Dublin, School of Chemistry } \\
\text { Angione, M. Daniela; Trinity College Dublin, School of Chemistry } \\
\text { Browne, Michelle; Queens University Belfast, School of Chemistry and } \\
\text { Chemical Enqinnerring } \\
\text { Hoque, Md. Khairul; Trinity College Dublin, School of Chemistry } \\
\text { Doyle, Thomas; National University of Ireland - Galway, School of Natural } \\
\text { Sciences and Marine and Renewable Energy Centre } \\
\text { Scanlan, Eoin; Trinity College Dublin, Chemistry } \\
\text { Colavita, Paula; Trinity College Dublin, School of Chemistry }\end{array}$ \\
\hline
\end{tabular}




\title{
Bioinspired Aryldiazonium Carbohydrate Coatings: Reduced Adhesion of
}

\section{Foulants at Polymer and Stainless Steel Surfaces in a Marine Environment}

\author{
Adam Myles, ${ }^{a}$ Damien Haberlin, ${ }^{b}$ Leticia Esteban-Tejeda, ${ }^{a}$ M. Daniela Angione, ${ }^{a}$ Michelle P. \\ Browne, ${ }^{a}$ Md. Khairul Hoque, ${ }^{a}$ Thomas K. Doyle, ${ }^{c}$ Eoin M. Scanlan ${ }^{a^{*}}$ and Paula E. Colavita ${ }^{a^{*}}$ \\ ${ }^{a}$ School of Chemistry, CRANN and AMBER Research Centres, Trinity College Dublin, College \\ Green, Dublin 2, Ireland \\ ${ }^{b}$ Marine and Renewable Energy Centre, Environmental Research Centre, University College \\ Cork, Beaufort Building, Haulbowline Road, Ringaskiddy, Cork, Ireland \\ ${ }^{c}$ School of Natural Sciences (Zoology), Ryan Institute and Marine and Renewable Energy \\ Centre, National University of Ireland Galway, Galway, Ireland \\ *Corresponding: colavitp@tcd.ie and eoin.scanlan@tcd.ie
}

Keywords: aryldiazonium, coatings, marine, fouling, functionalization, carbohydrates. 
Abstract

Surface treatments that minimise biofouling in marine environments are of interest for a variety of applications, such as environmental monitoring and aquaculture. We report on the effect of saccharide coatings on biomass accumulation at the surface of three materials that find applications in marine settings: stainless steel 316 (SS316), nylon-6 (N-6), and poly(ether sulfone) (PES). Saccharides were immobilized via aryldiazonium chemistry; SS316 and $\mathrm{N}-6$ samples were subjected to oxidative surface pre-treatments prior to saccharide immobilization, whereas PES was modified via direct reaction of pristine surfaces with the aryldiazonium cations. Functionalization was confirmed by a combination of X-ray photoelectron spectroscopy, contact angle experiments and fluorescence imaging of lectinsaccharide binding. Saccharide immobilization was found to increase surface hydrophilicity of all materials tested, while laboratory tests demonstrate that the saccharide coating results in reduced protein adsorption in the absence of specific protein-saccharide interactions. The performance of all three materials after modification with aryldiazonium saccharide films was tested in the field via immersion of modified coupons in coastal waters over a 20 day time period. Results from combined infrared spectroscopy, light microscopy, scanning electron and He-ion microscopy and adenosine-triphosphate content assays show that the density of retained biomass at surfaces is significantly lower on carbohydrate modified samples with respect to unmodified controls. Therefore, functionalization and field test results suggest that carbohydrate aryldiazonium layers could find applications as fouling resistant coatings in marine environments. 


\section{Introduction}

Materials immersed in natural waters are typically subject to biofouling, a process that can compromise the integrity of the material or device of interest and result in performance degradation. Structures which are submerged in a marine environment are particularly susceptible to a wide range of opportunistic fouling organisms, ${ }^{1,2}$ and material biofouling and colonization can have a negative impact in a wide range of fields, from marine transport to environmental monitoring and aquaculture. ${ }^{3-6}$ Marine biofilms result in major economic and environmental problems, from corrosion and loss of functionality of marine structures and vessels, ${ }^{7,8}$ to the spread of invasive species $^{9}$ and increased farmed fish mortality. ${ }^{10-12}$ Therefore, there is great interest in developing new strategies for preventing and mitigating biofouling in the marine environment, particularly non-toxic or non-biocidal strategies that are environmentally sustainable, commercially scalable and compatible with the modern regulatory landscape. ${ }^{1,3,4,13}$

Biofouling occurs through a complex mechanism that involves multiple processes over a range of time and length scales. ${ }^{13}$ It is proposed that, in the initial stages, the surface rapidly becomes conditioned by the adsorption of small molecules and organic matter, such as small organics, biopolymers and proteinaceous material. Microorganisms then adhere onto this primed surface eventually forming a biofilm onto which larger organisms can attach and subsequently proliferate. ${ }^{5}$ Accumulation of undesired biomass can be minimized by interfering at one or more of these stages of the biofouling cascade. Historic methods of biofilm mitigation involve the use of toxic coatings such as lead-based and organotin paints, ${ }^{14}$ which interfere at the micro- and macro-fouling stages. However, due to adverse effects on marine ecosystems, these methods have been phased-out and even use of 
alternative paints and coatings based on copper release is under regulatory scrutiny. The disruption of quorum sensing signals to inhibit/regulate biofilm formation potentially offers a more targeted approach than metal-based biocides; however, this technology is in its infancy and its environmental impact on ecosystems remains to be assessed. ${ }^{15}$

The most promising non-biocidal strategies, on the contrary, rely on modifying the physicochemical properties of submerged materials to minimise adsorption and adhesion mainly at early fouling stages. Regulation of surface roughness, electrostatic charge distribution and wetting behaviour have all been investigated as non-biocidal methods. ${ }^{13,16}$ Bioinspired engineered nanotopographies are effective for regulating cell/spore settling; however, complex hierarchical patterns are required to repel settling from heterogeneous populations, ${ }^{17}$ thus posing significant problems for cost-effective scalability. Regulation of wetting and spatial control of hydrophobicity at the nanoscale level have also been explored as antifouling mechanisms. Low surface free energy and hydrophobic materials and coatings have a long history in antifouling technologies and some well-known examples are polysiloxanes, fluoropolymers and superhydrophobic coatings. ${ }^{1,6,13,18,19}$ At the other end of the spectrum, hydrophilic coatings, such as those based on polyethylene glycols (PEGs ${ }^{20}$ and bioinspired superhydrophilic zwitterionic polymers, ${ }^{21,}{ }^{22}$ have similarly demonstrated good performance in laboratory tests.

Surface-immobilized carbohydrates have previously been investigated for the fabrication of hydrophilic coatings for biofouling prevention. Carbohydrates represent an interesting family of biomolecules because they are environmentally benign and because they are highly stable towards oxidation compared to other chemical species such as ethyleneglycols. $^{18,20,23}$ Previous work has shown that self-assembled monolayers (SAMs) of 
monosaccharides and di-saccharides on gold surfaces can greatly reduce fouling from protein solutions. ${ }^{24-27}$ More recently, Ederth et al. ${ }^{25}$ demonstrated that galactose-bearing SAMs were successful at reducing Ulva linza spore settling, thus showing promise for marine fouling control. Polysaccharides have also been investigated, however the efficient calcium binding affinity displayed by many of these, e.g. hyaluronic and pectinic acids, has been identified as detrimental for fouling control in the marine environment. ${ }^{28,29}$ Nonetheless, relative to other functional coatings, carbohydrates are underexplored in marine applications and results from field tests are rare in the literature.

We have recently shown that aryldiazonium chemistry offers a viable route for the immobilization of saccharides at carbon, metal and selected polymer surfaces. ${ }^{30}$ This immobilization strategy can be carried out from solution via spontaneous reaction, resulting in thin conformal functional films that can be applied via flow, spray or dip coating methods using aqueous solutions, thus making it attractive and feasible for large scale applications. Covalent grafting of mono- and disaccharide-bearing aryldiazonium cations to carbon, polydimethylsiloxane (PDMS) and polyethersulfone (PES) was found to significantly reduce protein adsorption in laboratory tests. ${ }^{31-33}$ Interestingly, in the case of PES surfaces the ability to prevent protein adsorption translated well to field tests, whereby aryldiazonium glycoside coatings were found to reduce biomass accumulation after prolonged exposure to wastewater effluents. ${ }^{33}$ These prior results strongly suggest that aryldiazonium carbohydrate coatings could be effective at minimising biofouling in the complex environment of natural waters; however, to the best of our knowledge these coatings have not been tested in marine settings. 
In this work we report a study of the performance of carbohydrates immobilized via aryldiazonium grafting as fouling resistant coatings on coupons of three different materials of technological importance: stainless steel, nylon and PES. Polyamide materials and metal alloys are used regularly in the marine environment and are particularly susceptible to marine fouling, while PES is a common membrane material used in aquatic sensors. Lactosides were chosen for immobilization via spontaneous aryldiazonium grafting, because of their lack of calcium-binding carboxylic acid residues, ${ }^{28}$ and on the basis of previously published comparative tests on the performance of simple glycosides. ${ }^{24,32,33}$ First, we report on the effectiveness of spontaneous functionalization reactions on the above substrates; second, we report the results of immersion tests in a coastal environment for 20 days over the summer period. Results from field tests indicate that carbohydrate coatings show promise as a sustainable and environmentally benign approach for reducing adhesion and retention of marine foulants.

\section{Experimental Methods}

Chemicals and Materials: Polyamide- Nylon 6 (N6) sheets, marine grade stainless steel 316 foil (SS316), and Polyethersulfone sheets (PES) were purchased from Goodfellow; formaldehyde solution for molecular biology $\geq 36.0 \%$ in $\mathrm{H}_{2} \mathrm{O}$, hypophosphorous acid solution $50 \%$ wt. in $\mathrm{H}_{2} \mathrm{O}$, sodium hypochlorite (bleach), sodium hydroxide, potassium hydroxide, phosphate buffered saline buffer (0.010 M PBS, pH 7.4), sodium nitrite, hydrochloric acid and fluoroboric acid were purchased from Sigma Aldrich. Aquasnap ATP Total Water testing strips were purchased from Water Technology Ltd. Bovine Serum Albumin (BSA) conjugates with Alexa Fluor 647 were purchased from Biosciences. Bovine Serum Albumin (BSA) and peanut agglutinin from Arachis Hypogaea (PNA) conjugates with fluorescein isothiocyanate (FITC) 

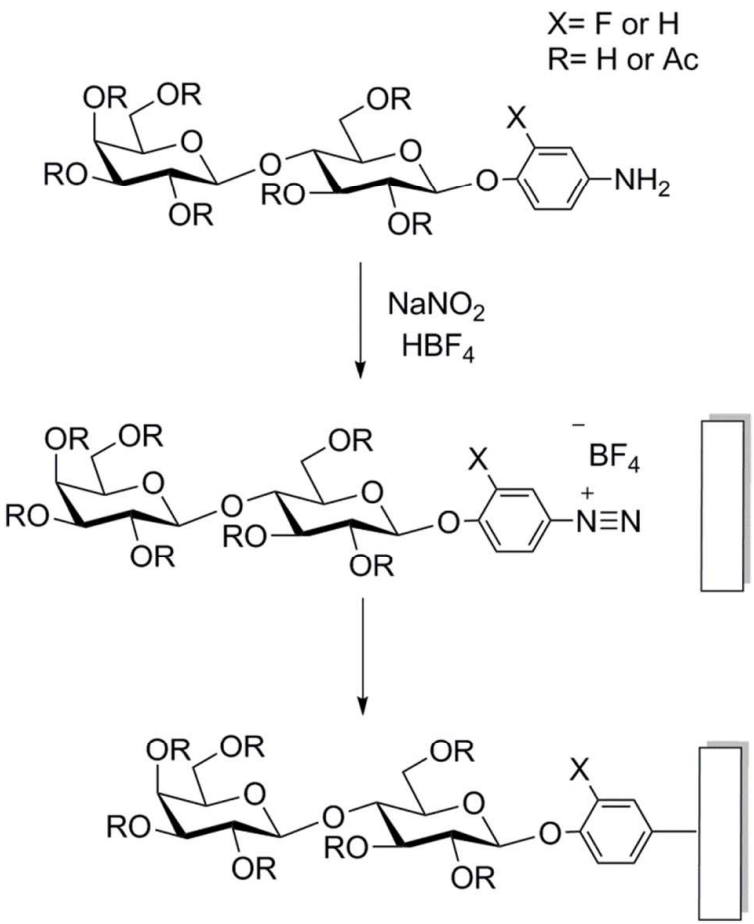

Scheme 1. 4-aminophenol- $\beta$-D-lactopyranose compounds used for all functionalized samples and reaction protocol used for diazotization and functionalization with aryldiazonium cations in situ.

were purchased from Sigma Aldrich. 4-aminophenol- $\beta$-D-lactopyranose and its fluorinated analogue 2-fluoro-4-aminophenol- $\beta$-D-lactopyranose (Scheme 1 ) were synthesized as previously described. ${ }^{30,33}$ The peracetylated lactoside 2-fluoro-4-aminophenyl- 2,3,4,6-tetraO-acetyl- $\beta$-D-galactopyranosyl-(1 $\rightarrow 4)-2,3,6$-tri-Oacetyl- $\beta$-D-glucopyranoside (Scheme 1$)$ was used for infrared experiments; synthesis and characterisation of this compound are reported in the Supplementary Information.

Surface modification: Prior to modification with aryldiazonium cations, both polyamide and stainless steel surfaces were pre-activated, while PES surfaces did not require preactivation $^{33}$ and were used after light cleaning in methanol only. Nylon-6 (N6) samples were pre-activated by overnight immersion at $30{ }^{\circ} \mathrm{C}$ in a $36 \%$ aqueous formaldehyde solution with a catalytic amount of hypophosphorous acid. Stainless Steel samples (SS316) were pre- 
treated with $0.5 \% \mathrm{NaClO}$ in basic aqueous solution $(\mathrm{KOH} 1 \%$ and $\mathrm{NaOH} 1 \%){ }^{32}$ surfaces were immersed three times in fresh solution for $10 \mathrm{~min}$ at room temperature. Samples were rinsed thoroughly with deionized water and functionalized via immersion in freshly prepared $1.0 \mathrm{mM}$ solutions of aryldiazonium cations generated in situ from the corresponding amine, 4-aminophenol- $\beta$-D-lactopyranose (Scheme 1 ), following previously published protocols. ${ }^{30}$ Briefly, a $1.25 \mathrm{mM}$ solution of the 4-aminophenol in $0.00150 \mathrm{M} \mathrm{HBF}_{4}$ was prepared and cooled to $4{ }^{\circ} \mathrm{C}$ or less in an ice bath for $1 \mathrm{~h}$. The cold precursor solution was diluted via addition of a $0.010 \mathrm{M} \mathrm{NaNO}_{2}$ to a final concentration of $0.0010 \mathrm{M}$ in 4aminophenol precursor, acid and nitrite. Samples were immersed immediately into the precursor solution and kept in the dark for $1 \mathrm{~h}$, then rinsed with deionized water and kept under wet storage in deionized water prior to further testing. For field studies a typical batch size for material modification was $3 \mathrm{~L}$, while laboratory experiments involved the preparation of $25 \mathrm{~mL}$ solutions. Functionalization using peracetylated precursors followed the same protocol except for the use of acetonitrile as a solvent; samples were rinsed using sonication in acetonitrile/methanol, a protocol that had been shown to be effective at removing physisorbed acetylated aryldiazonium glycosides. ${ }^{30}$

Surface Characterization: Water contact angles (WCA) were determined for all samples using the sessile drop method (FTA1000), using $20 \mu \mathrm{L}$ droplets. Infrared reflectance absorption spectroscopy (IRRAS) characterization was carried out on a Bruker Tensor 27 infrared spectrometer equipped with a mercury cadmium telluride detector and a VeeMax II specular reflectance accessory with a wire grid polariser. All spectra were collected using ppolarized light; 100 scans at $4 \mathrm{~cm}^{-1}$ were collected for all samples and an unmodified sample was used as substrate. X-ray photoelectron spectroscopy (XPS) was carried out on a VG 
Scientific ESCAlab MK II system with an Al Ka source at $90^{\circ}$ takeoff angle. Wide surveys and core level spectra were collected at 50 and $20 \mathrm{eV}$ pass energy, respectively. All spectra were calibrated to the $\mathrm{Cr} 2 \mathrm{p}_{3 / 2}$ peak of $\mathrm{Cr}_{2} \mathrm{O}_{3}$ present in the stainless steel substrate at $576.7 \mathrm{eV}$ (Figure S1). ${ }^{34,35}$ Fits were carried out using commercial software (CasaXPS) using Voigt line shapes and background correction; atomic ratios were calculated from peak areas after correction for relative sensitivity factors $\left(\mathrm{RSF}_{\mathrm{C} 1 \mathrm{~s}}=1 ; \mathrm{RSF}_{\mathrm{F} 1 \mathrm{~s}}=4.43 ; \mathrm{RSF}_{\mathrm{Cr} 2 \mathrm{p}}=11.7 ; \mathrm{RSF}_{\mathrm{Fe} 2 \mathrm{p}}=\right.$ 16.4). Optical depths were calculated from UV-Vis transmittance measurements (Lambda 35 Perkin Elmer). Scanning electron microscopy (SEM) images were obtained on a Karl Zeiss Ultra Field Emission SEM at accelerating voltages between 2-3 kV in secondary electron mode. Helium ion microscopy (HIM) was obtained on a Karl Zeiss NanoFab HIM at 0.2-0.6 pA beam currents and $30 \mathrm{kV}$ accelerating voltage, while sample charging was minimized using a flood gun.

Affinity binding and protein adsorption studies via fluorescence imaging. To determine protein rejection ability, samples of $\mathrm{N} 6$ and SS316 were incubated in $0.2 \mathrm{mg} \mathrm{mL}^{-1}$ solutions of BSA fluorescent conjugates in PBS at $\mathrm{pH} 7.4$ for $1 \mathrm{~h}$; Alexa-647 and FITC were the dyes used for N6 and SS316, respectively. To determine lectin binding affinity, samples of SS316 were incubated for $1 \mathrm{~h}$ in a $0.2 \mathrm{mg} \mathrm{mL}^{-1}$ solution of PNA-FITC conjugate in $\mathrm{pH} 7.4$ PBS buffer with $0.1 \mathrm{mM} \mathrm{CaCl}_{2}$ and $\mathrm{MgCl}_{2}$. All samples were washed with PBS solution prior to imaging to remove excess unbound protein. Fluorescence images were acquired using an Olympus BX51 inverted microscope with cellSense digital image processing software. Emission intensities were analysed in triplicate using Image J software. ${ }^{32}$

ATP determinations: Adenosine triphosphate (ATP) concentrations per square $\mathrm{cm}$ of substrate material were determined using the luciferase assay as implemented in a 
commercial kit (Aquasnap Total Water). ${ }^{36}$ The assay was first calibrated using standard solutions and the luminometer (Hygiena) to obtain a conversion from relative luminescence units (RLU) to ATP concentration (in $\mathrm{nM}$ range). Samples of approximately $1 \mathrm{~cm}^{2}$ were cut from each coupon in triplicate; the cutting was suspended in a known volume of deionized water (10 $\mathrm{mL}$ or $5 \mathrm{~mL}$, depending on level of fouling) in sterile centrifuge tubes and then sonicated for $10 \mathrm{~min}$. The value of RLU was determined for each water sample and converted to ATP concentrations; water samples were diluted if needed to bring the ATP concentration within the linear range of the assay. Post sonication, the cuttings were dried under argon and their mass determined; the relative exposed area was estimated from the mass of the cleaned sample cutting and this value was used to surface-normalise ATP determinations on individual cutting. Values were compared using ANOVA at 5\% significance level $(\alpha=0.05)$.

Coastal Immersion Study: Immersion studies were carried out on $24^{\text {th }}$ August 2016 in Bertraghboy Bay, County Galway, at the site of an unused salmon farming platform (Lehanagh pool). Following functionalization, 6 control and 6 functionalized coupons, $100 \mathrm{x}$ $100 \mathrm{~mm}^{2}$ in size, were transported within $24 \mathrm{~h}$ under wet storage to the testing site located at $150 \mathrm{~m}$ from the shore $\left(53.402267^{\circ} \mathrm{N}, 9.820329^{\circ} \mathrm{W}\right)$. Polyethylene frames on which N6, SS316 and PES coupons had been mounted were set up as shown in Figure 1a. Frames were transported by power boat to the testing site and suspended from the edge of the test site (Figure $1 \mathrm{~b}$ ) at a depth of approximately $1 \mathrm{~m}$, considered to be optimal for rapid biofouling. ${ }^{37}$ The frames were weighted to ensure that all samples would remain in a vertical position throughout the duration of the trial which lasted 20 days over the summer months (Aug 24 - Sept 13). The mean water temperature during the 20 day trial was $16.84 \pm 0.31{ }^{\circ} \mathrm{C}$ 

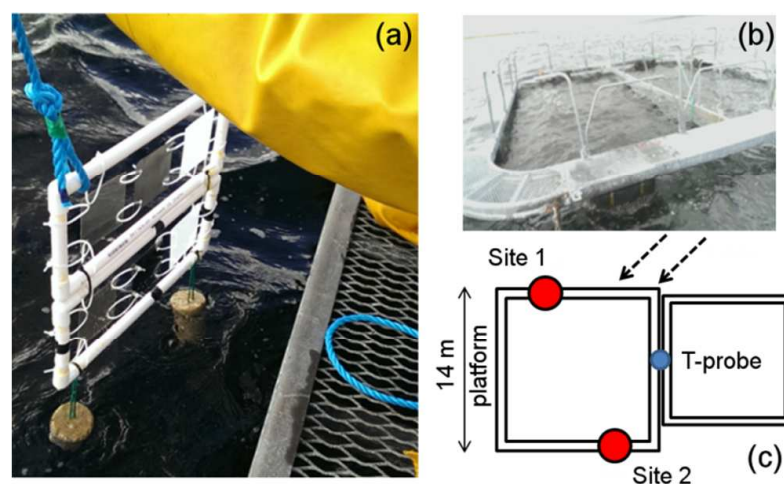

(b)

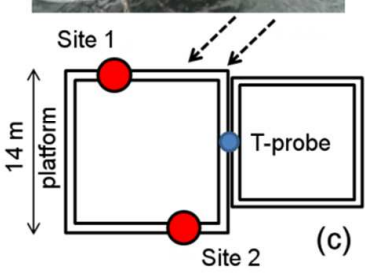

Figure 1. (a) Assembled frame with coupons, arranged from left to right, PES, SS316 and N6, immediately prior to immersion in sea water. (b) Salmon farm platform from which frames with coupons were suspended. (c) Scheme showing the two adjacent platforms and the location of frames at Site 1 and Site 2 relative to the tide (dashed arrows); a temperature probe measured surface water temperature at the position indicated in blue.

(maximum $18.20^{\circ} \mathrm{C}$, minimum $16.23^{\circ} \mathrm{C}$ ), measured from readings at $1 \mathrm{~m}$ depth (StowAway TidbiT). Two positions were chosen for suspending the frames: these are denoted as site 1 and site 2 and are mapped to the platform configuration in Figure 1c. Three samples of each control and functionalized coupon were mounted at each site, i.e. a total of 12 coupons, 4 of each material distributed over the two sites. After the 20 day test, all samples were transported to the laboratory immersed in seawater prior to testing. Samples were rinsed under a stream of deionized water delivered $10 \mathrm{~cm}$ above the sample by gravity for $30 \mathrm{~s}$ on each side. This procedure was used across all samples to remove loosely attached biomass. Samples were analysed immediately or stored frozen for further characterization.

\section{Results}

\section{Aryldiazonium modification of Stainless Steel and Nylon coupons}

Coupons of polyethersulfone (PES), stainless steel (SS316) and Nylon-6 (N6) were first modified using lactoside groups via spontaneous reaction of aryldiazonium cations to yield 
Nylon-6

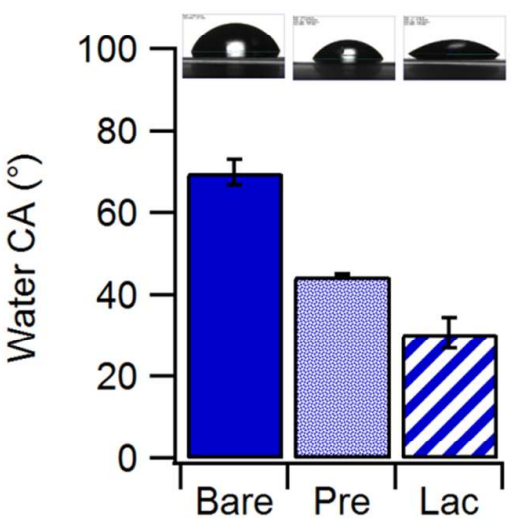

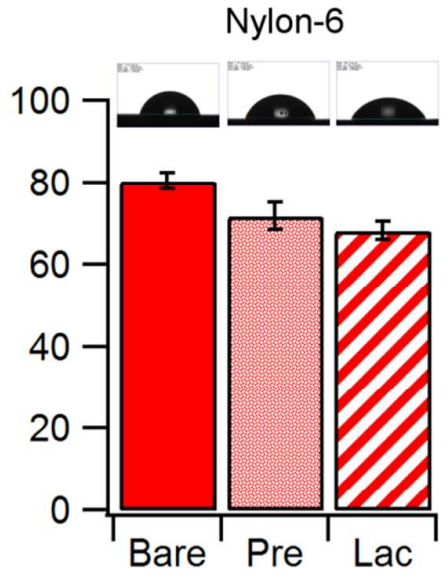

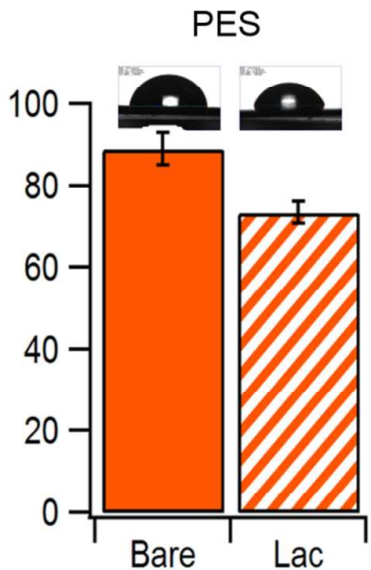

Figure 2. Water contact angle values obtained on bare, pre-treated (except for PES) and Lactosemodified (Lac) surfaces of SS316, Nylon-6 and PES. Samples were pre-activated in caustic bleach and formaldehyde solutions in the case of SS316 and nylon-6, respectively.

surfaces denoted as Lac-PES, Lac-SS and Lac-N6. Aryldiazonium cation solutions were freshly prepared immediately prior to functionalization following standard diazotization protocols; briefly, the arylamine compound was reacted with sodium nitrite in acid aqueous solution at $4{ }^{\circ} \mathrm{C}$ (Scheme 1) yielding the corresponding aryldiazonium cation, a highly reactive species.

Work from our group demonstrated that PES undergoes functionalization by spontaneous reaction after immersion of pristine substrates in these solutions and we refer to our previous publication for a full characterization of Lac-PES surfaces thus obtained. ${ }^{33}$ In the case of SS316 and N6, surfaces were pre-activated prior to functionalization. SS316 surfaces were pre-activated in caustic hypochlorite (bleach) solutions; this treatment is known to have cleaning and oxidising effects on SS316 surfaces. ${ }^{38-40} \mathrm{~N} 6$ surfaces were pre-treated by immersion in formaldehyde solutions, which are known to activate amide groups in polyamides via formation of $\mathrm{N}$-methylol groups. ${ }^{36,41,42}$ Pre-activation treatments were found to increase surface hydrophilicity as evident from a marked change in water contact angle (Figure 2). The WCA of SS316 decreases from $69.8^{\circ}$ to $44.5^{\circ}$, as expected from 
oxidative cleaning of adventitious organics and exposure of a hydrophilic oxide film. ${ }^{43}$ The WCA of nylon also decreases from a value of $80.4^{\circ}$, in agreement with literature values for pristine N6, to $71.7^{\circ}$; this is consistent with an increase in the surface density of hydroxyl groups resulting from formaldehyde treatment. Coupons of all three materials tested displayed a significant change in WCA after immersion in the aryldiazonium cation solution. Figure 2 shows that all surfaces decreased their WCA, as expected from the immobilization of hydrophilic saccharide groups and in agreement with previous reports on the effect of lactoside immobilization. $^{31}$

Lactoside immobilization was further confirmed using binding studies using PNA lectin. PNA is known to display binding affinity towards galactose ${ }^{44}$ and can be used to confirm the presence of surface-bound lactosides as these display an available galactose unit at the solid-liquid interface. Lac-SS and Lac-N6 coupons were incubated for $1 \mathrm{~h}$ in a solution of fluorescently labeled PNA and rinsed with PBS prior to imaging; Figure 3 shows fluorescence microscopy images of pre-treated and Lac-modified surfaces after PNA incubation and a 

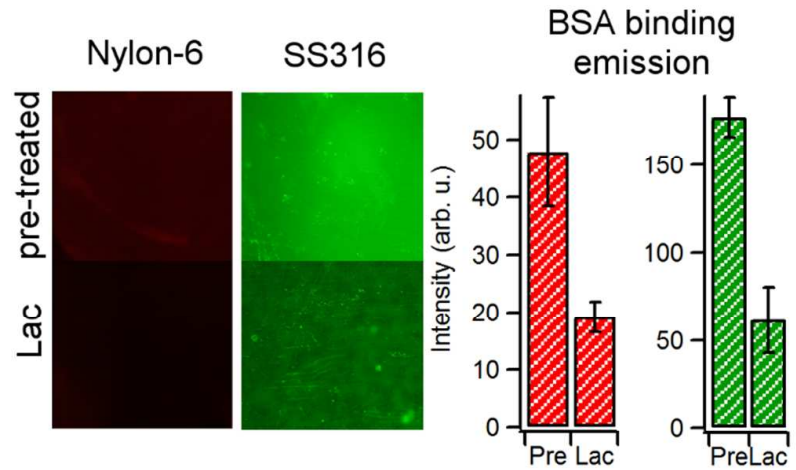

Figure 4. Fluorescence images obtained after protein adsorption experiments using dye-conjugated BSA on Nylon- 6 and SS316 after pre-treatment and after aryldiazonium modification with lactosides (Lac). The images show that the emission intensity is lower on lactose-modified surfaces. Bar plots represent average emission intensities of Alexa-BSA on Nylon-6 (red bars) and of FITC-BSA on SS316 (green bars) obtained at pre-treated (Pre) and at lactose-modified coupons (Lac).

comparison of average emission intensities. The stronger emission observed for surfaces after reaction with aryldiazonium cations indicates preferential specific binding with respect the corresponding bare pre-treated surface and is therefore supporting of functionalization. No evidence of modification was found in the absence of pre-treatment for either SS316 or N6 surfaces.

Protein adsorption experiments were also carried out using fluorescently labeled BSA, a protein that does not display specific binding with glycosides. Figure 4 shows images of pretreated and Lac-modified SS316 and N6, together with a summary of average emission intensity values obtained using BSA on pre-treated and modified coupons. After functionalization with lactosides a decrease in emission is observed compared to the pretreated surface, thus indicating that less BSA adsorbs at Lac-SS and Lac-N6 surfaces. This indicates, first, that the increase in fluorescence observed for Lac-SS and Lac-N6 after incubation in PNA solutions is the result of specific Gal-PNA interactions. Second, that immobilization of small saccharides leads to a decrease in unspecific protein binding, in 
agreement with observations on the effect of glycoside coatings on carbon and other polymer surfaces. $^{31,33}$

In the case of SS316, functionalization was also confirmed using the fluoro-substituted derivative of the lactoside precursor shown in Scheme 1, as the presence of fluorine substituents provides good elemental contrast between the functional layer and the bare substrate. Survey spectra of pre-treated and modified SS316 in Figure 5a show the characteristic peaks of stainless steel associated with Fe $2 p, \mathrm{Cr} 2 p, \mathrm{Ni} L \mathrm{LM}, \mathrm{O} 1 \mathrm{~s}$, and C $1 \mathrm{~s}$ lines. $^{45,46}$ Figures $5 b$ and $5 c$ show the spectra of SS316, in the $F 1 s$ and $C$ 1s regions, respectively, after pre-treatment and after surface modification in solutions of the fluorinated aryldiazonium lactoside.

Analysis of peak area ratios and fitting of the $C$ 1s line yielded results summarised in Table 1. The pre-treated SS316 surface shows $\mathrm{C} / \mathrm{Cr}$ and $\mathrm{Cr} / \mathrm{Fe}$ atomic ratios that are consistent with those observed for plasma cleaned SS316 by Williams et al. ${ }^{46}$ the surface was found to be Cand $\mathrm{Cr}$-rich with respect to the bulk composition, in agreement with previous compositional studies. ${ }^{34}$ Deconvolution of the $\mathrm{C} 1 \mathrm{~s}$ line shows the presence of four main peaks at $285.3 \mathrm{eV}$ ( $\mathrm{C}-\mathrm{C}$ and $\mathrm{C}-\mathrm{H})$, at 286.8 and $288.7 \mathrm{eV}(\mathrm{C}-\mathrm{O})$, and at $289.9 \mathrm{eV}(\mathrm{C}=\mathrm{O})$, in agreement with previous reports for stainless steel surfaces. ${ }^{47}$ After functionalization, a clear peak is evident at $687.0 \mathrm{eV}$ consistent with the $\mathrm{F}$ 1s binding energy of fluorinated organics, where $\mathrm{F}$ atoms are in a low F/C content environment. ${ }^{48,49}$ Identical changes were obtained in the $\mathrm{F}$ 1s region after functionalization using chloride as a counterion (Figure S2), thus confirming that the F 1s peak does not arise from tetrafluoroborate contamination. Therefore, this result suggests that after functionalization the aryl group is bound to the SS316 surface. The conclusion is further supported by an increase of the $C$ s peak intensity relative to the $\mathrm{Cr} 2 \mathrm{p}$ 

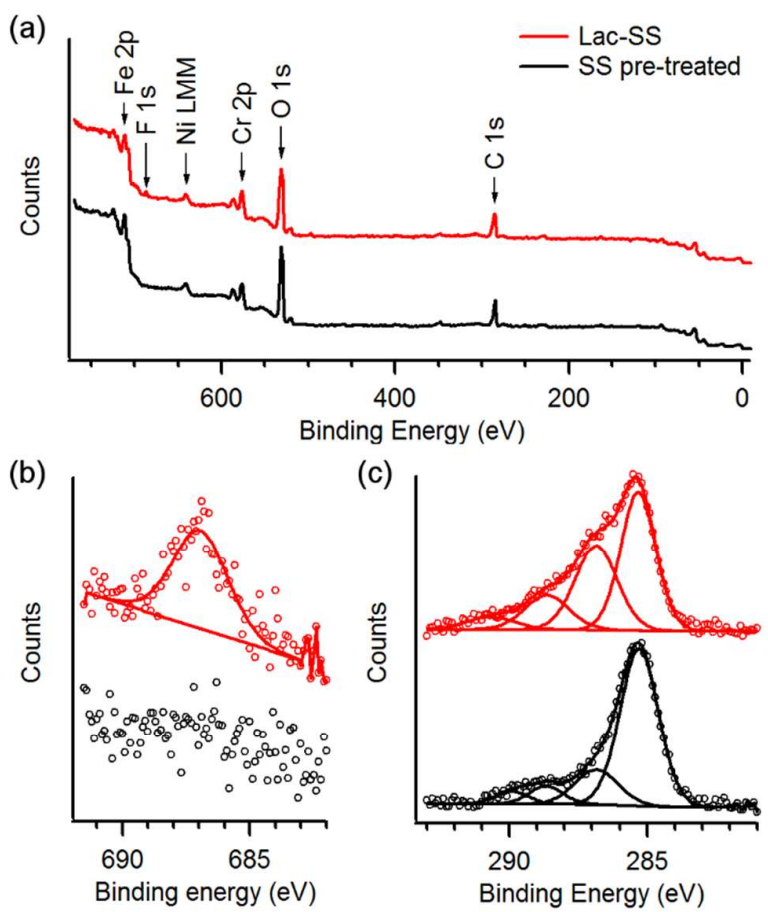

Figure 5. (a) Survey XPS spectra of SS316 after pre-treatment (black) and after modification with Fsubstituted aryl-lactoside (red). (b) F 1s and (c) C 1s high resolution spectra; these spectra show that upon reaction with aryldiazonium lactosides there appear peak contributions at $687 \mathrm{eV}$ and at 286$289 \mathrm{eV}$ that can be attributed to F-atoms and C-O groups, respectively.

Table R1. Summary of results from XPS analysis of spectra in Figure 5. Values in parentheses indicate $\%$-contribution to the total peak intensity; elemental ratios are calculated as atomic ratios.

\begin{tabular}{lcc}
\hline & SS pre-treated & Lac-SS \\
\hline C 1s (eV) & $285.3(70 \%)$ & $285.1(46 \%)$ \\
& $286.8(18 \%)$ & $286.7(33 \%)$ \\
& $288.7(7 \%)$ & $288.4(15 \%)$ \\
& $289.9(5 \%)$ & $290.5(6 \%)$ \\
F 1s (eV) & - & 687.0 \\
\hline C/Cr at. & 6.9 & 7.6 \\
F/Cr at. & - & 0.30 \\
Cr/Fe at. & 0.67 & 0.68 \\
\hline
\end{tabular}


signal, which arises from the substrate alloy. The fit of the $C 1$ s line of Lac-SS (Figure $5 c$ ) shows (a) the appearance of a contribution at $290.5 \mathrm{eV}$, consistent with the binding energy expected for a C-F group; ${ }^{48,50,51}$ and (b) increased emission in the region 286-289 eV consistent with greater surface density of $\mathrm{C}-\mathrm{O}$ containing groups and with the presence of surface bound glycosides. The RSF corrected peak area ratio $\left(A_{286}+A_{288}\right): A_{687}=12.2$ is in good agreement with the $12: 1$ ratio of $\mathrm{C}-\mathrm{O}$ to $\mathrm{C}-\mathrm{F}$ expected from the molecular stoichiometry of the fluorinated precursor, thus confirming the assignment of peaks in the region 286-289 $\mathrm{eV}$ to, predominantly, $\mathrm{C}-\mathrm{O}$ groups from the lactoside, with likely minor contributions from substrate carbon. These results therefore indicate that the functionalization protocol resulted in surface modification of SS316 with aryl-lactosides.

An estimate of the molecular density can be obtained by assuming that the SS316 substrate surface consists of $\mathrm{Cr}_{2} \mathrm{O}_{3} / \mathrm{Fe}_{2} \mathrm{O}_{3}$ with $40 \% \mathrm{Cr}_{2} \mathrm{O}_{3}$ content $(\mathrm{Cr} / \mathrm{Fe}=0.67)$, as calculated from XPS and in agreement with Williams et al. ${ }^{46}$ Considering that both $\mathrm{Cr}_{2} \mathrm{O}_{3}$ and $\mathrm{Fe}_{2} \mathrm{O}_{3}$ have a density of $5.2 \mathrm{~g} \mathrm{~cm}^{-3}$, the photoelectron attenuation depth of $\mathrm{Cr} 2 \mathrm{p}$ photoelectrons can be predicted to be $\lambda=1.5 \mathrm{~nm}$ using Gries' G-1 predictive formula. ${ }^{52}$ Under the assumption that no photoelectrons escape from depths $>3 \lambda$, the average experimental $\mathrm{F} / \mathrm{Cr} 0.17 \pm 0.10$ atomic ratio measured over 5 samples yields an estimated mean density of $1.9 \times 10^{-9} \mathrm{~mol} \mathrm{~cm}-$ ${ }^{2}{ }^{53}$ For a perfectly smooth surface, this coverage is equivalent to $<5$ monolayers of lactosides. ${ }^{30,54}$ Given that the microscopic roughness factor of unpolished SS316 is $>1$, the estimated coverage value suggests the presence of a relatively sparse lactoside layer, as expected from a spontaneous reaction of the oxide surface with these bulky aryldiazonium cations and consistent with thin molecular layers formed on carbon substrates via similar protocols. $^{31}$ 


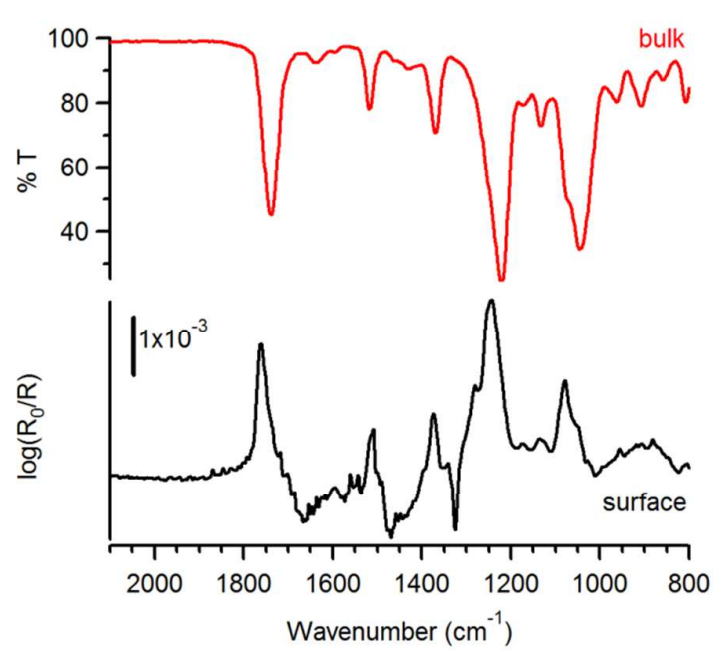

Figure 6. Infrared transmittance spectrum of a peracetylated aminophenol lactoside precursor (red, top) and IRRAS spectrum at $80^{\circ}$ incidence of the organic layer obtained after modification of a SS316 sample (black, bottom) with the same aryldiazonium precursor. The IRRAS spectrum displays the characteristic peaks of the precursor compound; peak assignments are discussed in the main text.

Finally, functionalization of SS316 surfaces was confirmed using a peracetylated analog of the aminophenol lactoside precursor (see Scheme 1): acetyl moieties serve as infrared labels thanks to their intense infrared absorbances. ${ }^{30}$ Figure 6 shows the IRRAS spectrum of a SS316 sample after functionalization (surface, bottom trace), compared to the transmittance spectrum of the peracetylated phenyl-glycoside precursor compound (bulk, top trace). ${ }^{30}$ The IRRAS spectrum displays the characteristic peaks of acetyl groups at 1760 $\mathrm{cm}^{-1}$ (C=O stretching), $1373 \mathrm{~cm}^{-1}\left(\mathrm{CH}_{3}\right.$ bending) and $1246 \mathrm{~cm}^{-1}$ (C-O-C asymmetric stretching)..$^{55}$ The peak centered at $1080 \mathrm{~cm}^{-1}$ is associated with $\mathrm{C}-\mathrm{O}$ stretching modes of the carbohydrate ring, while the peak at $1510 \mathrm{~cm}^{-1}$ arises from $\mathrm{C}-\mathrm{C}$ skeletal vibrations of phenyl rings. $^{33,55}$

In summary, the functionalization protocol outlined in Scheme 2 was found to be successful at grafting lactoside groups via spontaneous reactions of aryldiazonium cations onto SS316 


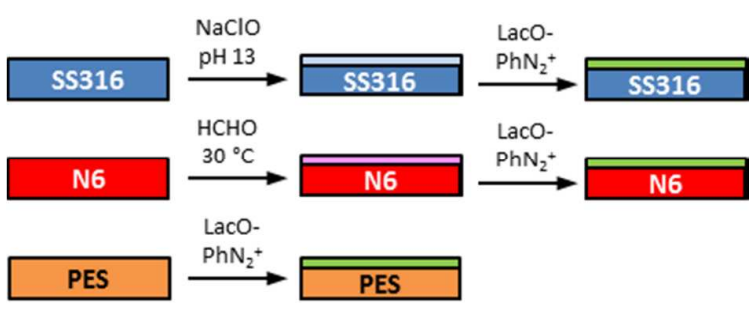

Scheme 2. Protocol used for the modification of SS316, N6 and PES.

and N6 surfaces. To the best of our knowledge this is the first reported protocol for the modification of nylon using aryldiazonium cations. It is interesting to note that the pretreatment protocol results in the formation of $-\mathrm{OH}$ groups and it is therefore likely that the functionalization mechanism involves nucleophilic attack of the hydroxyl onto the electron deficient para position of the aryl ring, in analogy to the $\mathrm{S}_{\mathrm{N}} 1$ hydrolysis mechanism of aryldiazonium cations (see Scheme S1). ${ }^{56}$ As regards stainless steel functionalization, most previous reports make use of cathodic electrografting reactions that can be driven even in the presence of a continuous passive oxide. ${ }^{57-59}$ Small et al. ${ }^{60}$ recently reported on the spontaneous attachment of fluorinated aryldiazonium salts on stainless steel from solution, achieved by polishing samples immediately prior to modification. Mechanical polishing breaks down the steel passive oxide, exposing the iron-rich underlayer which can act as an effective spontaneous reductant in aryldiazonium grafting, in agreement with findings on various oxide-free metals. ${ }^{61}$ In our case we have carried out an oxidising pre-treatment which is expected to yield instead a homogeneous hydrophilic passive oxide that cannot directly reduce the aryldiazonium cation; nonetheless, this oxide surface offers a high density of functional $\mathrm{M}-\mathrm{OH}$ and/or $\mathrm{M}-\mathrm{OOH} \operatorname{sites}^{60,62}$ available to chemical reaction. There are few reports of spontaneous aryldiazonium reactions on oxides, ${ }^{63,64}$ however the spontaneous formation of M-O-Ar bonds has been demonstrated experimentally. ${ }^{64}$ Based 
on our results, spontaneous grafting can take place on passivated stainless steel surfaces via aryl group cross-linking. It is likely that, as in the case of reactions with primary alcohols, functionalization proceeds via nucleophilic substitution involving oxide hydroxyl groups (see Scheme S1). ${ }^{56}$

\section{Field tests of bare and lactose-modified surfaces}

Control and lactose-modified coupons remained immersed in coastal waters for 20 days at the end of which samples were taken out of the water and the amount of biomass accumulated on the coupons was compared using a combination of optical and scanning microscopies, ATP content analysis, IRRAS in the case of SS316 and optical transmission in the case of PES. After immersion minimal differences were observed among different coupon materials, and between lactose-modified samples and unmodified controls of the same material upon visual inspection (Figure S3). However, after controlled light rinsing it was possible to observe clear and significant differences between coated and uncoated samples as discussed below.

Figure 7 shows representative optical microscopy images of SS316, nylon-6 and PES coupons positioned at site 1 , together with images of a corresponding pristine surface that had not undergone immersion; images of coupons at site 2 showed a similar trend (Figures S4-S6). Samples that had been coated with the aryldiazonium layer of lactoside units were found to display a visibly lower density of foulants. Unmodified samples in Figure 7 (top row) appear to show the evidence of secondary adhesive structures (algae pads or stalks), ${ }^{65}$ which are mostly absent in Lac-modified samples (middle row), and that are important for the development of microbial slimes. Figure 8 shows images at higher resolution obtained by 

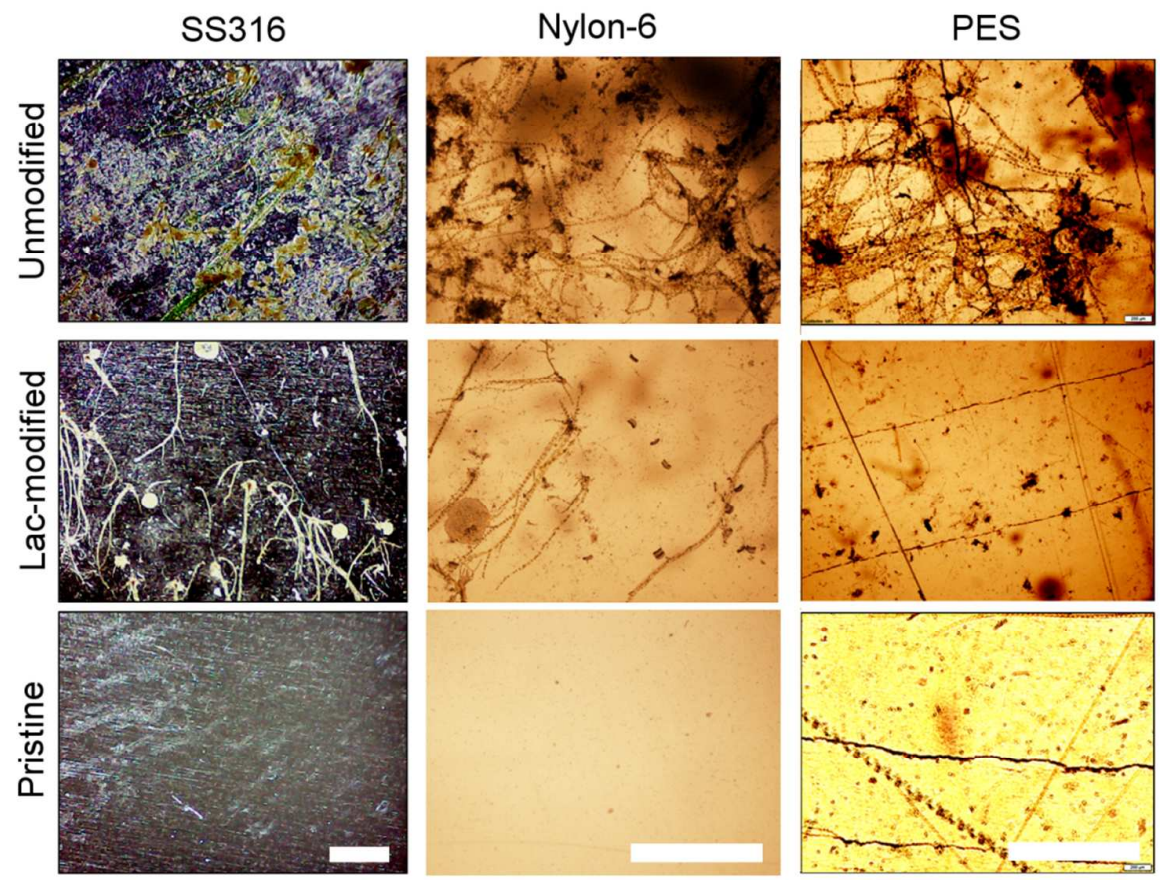

Figure 7. Optical microscope images of coupons of SS316, Nylon-6 and PES (scalebar $=1 \mathrm{~mm}$ ) extracted after 20 day immersion in coastal waters at site 1 (see Figure 1); samples were rinsed under the same conditions prior to imaging. The top row shows images of coupons that had not been coated with an aryldiazonium layer of glycosides; the middle row shows coupons that had been coated with a layer of lactosides prior to immersion; the bottom row shows samples as supplied by the vendor, without undergoing any immersion tests. All immersed samples display biomass accumulation however the density of adhered organic matter appears to be higher on unmodified when compared to lactoside-modified samples.

SEM and HIM microscopies on SS316 and polymer coupons, respectively. It is possible to observe the presence of diatoms and mucilaginous trails; visual inspection suggests that pennate diatoms dominate the retained deposits, in agreement with typical findings in marine fouling experiments. ${ }^{65}$ Scanning microscopy images also confirmed that a higher density of foulants remained adhered to the unmodified coupons compared to the modified ones for all tested materials.

Total ATP is an indicator of microbial biomass content and can be used to assess biomass accumulation at surfaces. ${ }^{66}$ Samples of known size taken from coupons were immersed into identical volumes of deionized water and sonicated to extract adsorbed biomass; a 

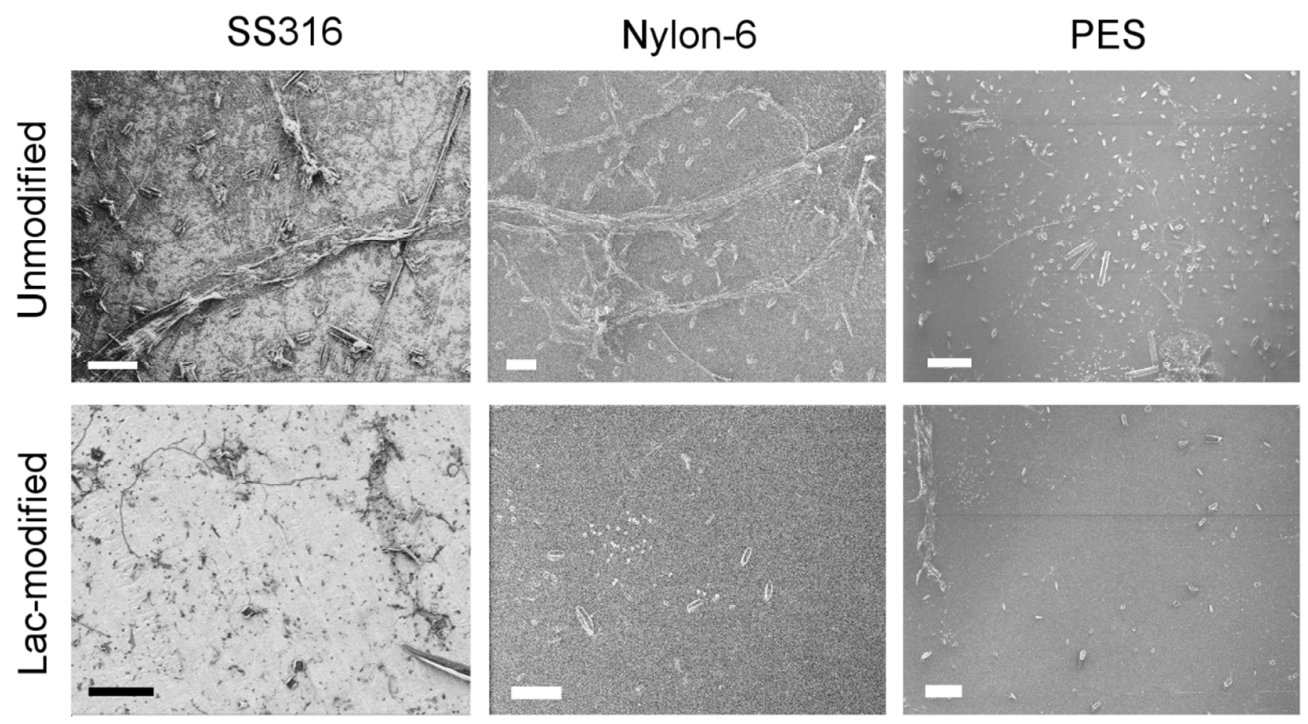

Figure 8. Microscopy images of coupons of SS316 (SEM, scalebar = $40 \mu \mathrm{m})$, Nylon-6 (HIM, scalebar = $40 \mu \mathrm{m}$ ) and PES (HIM, scalebar $=100 \mu \mathrm{m}$ ). The figures show details of surfaces after 20 day immersion in coastal waters followed by rinsing under identical conditions prior to imaging. The top row shows images of coupons that had not been coated with an aryldiazonium layer of glycosides; the bottom row shows coupons that had been coated with a layer of lactosides prior to immersion.

commercial bioluminescence assay was used in order to compare the ATP content extracted from control and lactose-modified samples. All RLU values were determined in deionized water and dilution factors were chosen which ensured that measurements fell within the linear dynamic range of the assay ${ }^{67}$ this procedure allowed for a conversion of RLU values to ATP concentrations in the extract and subsequent conversion to ATP mass released per unit area. Figure 9a shows a summary of ATP determinations obtained for SS316, nylon-6 and PES surfaces after immersion tests and prior to any rinsing. A comparison of ATP values indicates that biofilm accumulation was unaffected by the nature of the substrate material, with similar values obtained for SS316, N6 and PES coupons $(P=0.18)$. ATP values were found to be similar for control and modified coupons; in the case of SS316, results suggest a beneficial effect from the coating $(P=0.08)$ at a slightly higher significance level that might be clarified by further studies with a larger sample size. 

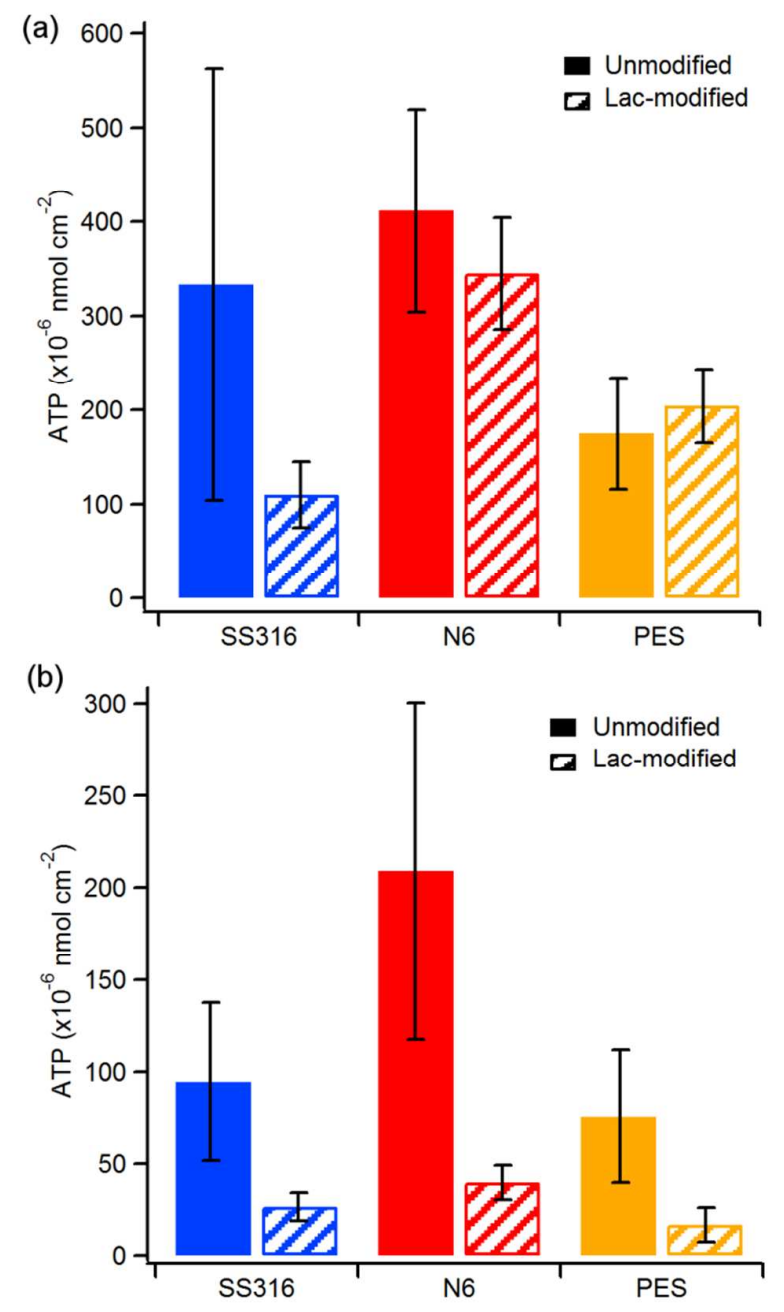

Figure 9. Average ATP released per unit area from unmodified (solid) and lactose-modified (striped) SS316, nylon- 6 and PES coupons after 20 day immersion tests in coastal waters prior to any rinsing (a) and after controlled rinsing (b). Error bars indicate $90 \%$ C.I.

Figure 9b shows a comparison of ATP values obtained at the three surfaces after controlled rinsing. The level of ATP measured at unmodified (control) surfaces was found to vary depending on the material, with results indicating that nylon- 6 retains the highest levels of biomass. A comparison between control and lactose-modified samples clearly shows that surfaces coated by carbohydrate layers have significantly lower amounts of retained biomass; this was confirmed in the case of SS316 $(P=0.04), \mathrm{N} 6(P=0.03)$ and PES $(P=0.04)$. 


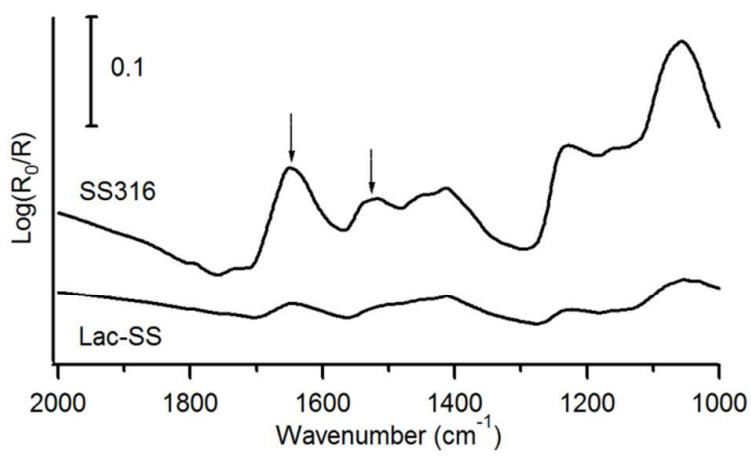

Figure 10. IRRAS spectra at $45^{\circ}$ incidence of SS316 unmodified sample and lactose-modified SS316 after 20 day immersion tests; this specific sample was located at site 2 however in all cases unmodified samples show more intense absorption peaks. Arrows indicate peaks at $1645 \mathrm{~cm}^{-1}$ and $1525 \mathrm{~cm}^{-1}$ corresponding to amide I and amide II modes, respectively.

The controlled rinsing process resulted in a reduction of ATP for all samples, however, the effect is noticeably greater in the case of lactose-modified surfaces yielding reductions of 75\%, 89\% and 92\% for SS316, nylon-6 and PES, respectively. These results therefore indicate that the lactoside layer has a strong impact on the ability of foulants to adhere to the material surface, thus improving resistance to biomass retention; this effect is particularly evident in the case of the two polymers tested.

IRRAS analysis was carried out to compare biomass accumulation at control and modified SS316; this was not possible in the case of N6 and PES due to the poor reflectance of these substrates. Figure 10 shows representative IRRAS spectra in the amide region of both a control and a lactose-modified SS316 sample after rinsing. The spectra show peaks at 1640 $\mathrm{cm}^{-1}$ and $1530 \mathrm{~cm}^{-1}$ which are assigned to the amide I and amide II modes, respectively, of polypeptides. ${ }^{55}$ These peaks display higher intensity for unmodified SS316, thus indicating that the surface density of proteinaceous material accumulated on control surfaces is higher than on lactose-modified surfaces. 


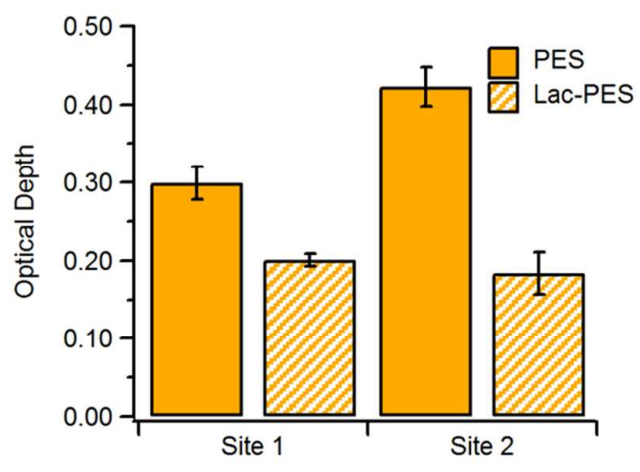

Figure 11. Optical depth of PES coupons at $600 \mathrm{~nm}$ measured after 20 day immersion test followed by controlled rinsing. Lac-modified samples are more transparent than unmodified ones.

PES coupons used in our studies were optically transparent, therefore, a quantitative assessment of biomass accumulation could also be obtained through measurements of optical depth $(-\ln (T))$. Figure 11 shows a comparison of the optical depth at $600 \mathrm{~nm}$ measured through PES coupons using a pristine PES sample as background: lactose-modified samples were more transparent than unmodified ones, and independently of the site tested, displayed significantly lower optical depth than the corresponding control sample. These results are in agreement with ATP determinations and with microscopy observations. Carbohydrate layers prepared via aryldiazonium chemistry are molecular coatings in the 1-2 $\mathrm{nm}$ thickness range that preserve the topography of the original substrate, ${ }^{31,33}$ so that their main effect is expected to be on surface chemistry and free energy. Results from field experiments show that in the absence of rinsing these coatings do not significantly impact on fouling resistance and little difference is observed with controls. Coupons extracted after the 20 day immersion were significantly fouled by a mixture of organisms and the presence of the coating did not affect marine biofilm formation. However, the accumulated biomass 
was dramatically reduced at carbohydrate-modified surfaces after only light rinsing by gravity driven streams. SEM and HIM imaging of samples showed that rinsing leaves a relatively clean surface, indicating effective detachment of the biofilm under very mild treatment. Therefore, these carbohydrate coatings were found to be effective at reducing adhesion of foulants on all three materials tested.

Recent field tests of coatings based on zwitterionic polymers by Hibbs et al. ${ }^{68}$ resulted in similar findings: zwitterionic coatings were found to affect foulant retention after jet rinsing, rather than to alter the amount of biomass accumulated on the coupons over the testing period. The striking agreement with our trends suggests analogies in the mode of action of carbohydrate thin films: these are thought to control fouling by regulating surface hydration, which is a similar mechanism to that proposed for zwitterionic polymers, ${ }^{1}$ albeit in the absence of a change in surface electrostatic charge. It has been proposed that the exact distribution of charged regions in zwitterionic coatings might play a role in modulating settlement behaviour; ${ }^{68}$ it would be therefore relevant to carry out similar experiments to those by Aldred et al. ${ }^{22}$ on settlement behaviour to investigate whether glycoside structure and presentation could be similarly leveraged in carbohydrate coatings.

\section{Conclusions}

Functionalization and field test results suggest that carbohydrate aryldiazonium layers could find applications as fouling resistant coatings. For all materials tested, the density of retained biomass at surfaces was found to be significantly lower on carbohydrate modified samples with respect to unmodified controls. The mode of action of these layers appears to affect biofilm adhesion rather than biofilm formation, operating via fouling release rather than via antifouling mechanisms. It is recognized that fouling minimization in natural 
seawaters is extremely challenging due to the presence of multiple organism populations with a wide range of adhesion mechanisms. ATP tests suggest that fouling resistance observed for lactoside-aryldiazonium layers is comparable to that observed for more chemically complex coating systems in laboratory assays, which use populations containing a single organism. It is therefore significant that the promising results herein reported were obtained in coastal waters, over prolonged times of exposure and during the summer months, when fouling activity is maximized.

Given the marked differences in physico-chemical properties among SS316 and the two polymers it is also encouraging to observe similar trends independent of material, as it suggests potential applicability on a variety of devices, including devices consisting of mixed materials. Although comprehensive fouling control remains elusive, our experiments indicate that thin carbohydrate layers could enhance the effectiveness of other fouling control methods. For instance, they could be easily combined/integrated with topographybased antifouling strategies, as they coat surfaces conformally with few molecular layers; or be combined with mechanical methods to reduce power consumption associated to foulant removal. The observed performance, together with the complete absence of toxicity and environmental impact of glycan based coatings make them attractive as a sustainable fouling mitigation strategy.

\section{Supporting Information}

Additional XPS spectra; details of compound synthesis, proposed functionalization mechanism; comparison of coupons in the absence of rinsing and immersed at the two different sites. This material is available free of charge via the Internet at 


\section{Corresponding Authors}

*E-mail: COLAVITP@tcd.ie; eoin.scanlan@tcd.ie

\section{Funding Sources}

This publication has emanated from research conducted with the financial support of Science Foundation Ireland (SFI) grant No. 12/RC/2278 and 12/RC/2302; AM acknowledges support from the School of Chemistry.

\section{Notes}

Some of the authors are co-inventors of patent filings covering selected aspects in this article.

\section{Acknowledgements}

The authors are grateful to T. McDermott, D. Jackson and F. Kane of the Marine Institute Ireland and Majbritt Bolton-Warberg of Carna Research Station (NUIG) for access to boating equipment and coastal testing facilities. The authors are also grateful to J. Headlam and A. Long (NUIG) for their assistance during the sampling periods. The authors also thank Dr. J. O’Brien, Dr. M. Ruether, Dr. M. Feeney, Dr. G. Hessman and Dr. S.N. Stamatin for assistance with NMR, MS and XPS characterization. The authors acknowledge Advanced Microscopic Laboratory (AML) and D. Daly of Trinity College Dublin for providing access to SEM and HIM.

\section{References}

1. Callow, J. A.; Callow, M. E., Trends in the development of environmentally friendly fouling-resistant marine coatings. Nat. Commun. 2011, 2, 244.

2. Fitridge, I.; Dempster, T.; Guenther, J.; de Nys, R., The impact and control of biofouling in marine aquaculture: a review. Biofouling 2012, 28 (7), 649-669. 
3. Cao, S.; Wang, J.; Chen, H.; Chen, D., Progress of marine biofouling and antifouling technologies. Chin. Sci. Bull. 2011, 56 (7), 598-612.

4. Chambers, L. D.; Stokes, K. R.; Walsh, F. C.; Wood, R. J. K., Modern approaches to marine antifouling coatings. Surf. Coat. Technol. 2006, 201 (6), 3642-3652.

5. Yebra, D. M.; Kiil, S.; Dam-Johansen, K., Antifouling technology-past, present and future steps towards efficient and environmentally friendly antifouling coatings. Prog. Org. Coat. 2004, 50 (2), 75-104.

6. Whelan, A.; Regan, F., Antifouling strategies for marine and riverine sensors. J. Environ. Monit. 2006, 8 (9), 880-886.

7. Videla, H. A.; Characklis, W. G., Biofouling and microbially influenced corrosion. Int. Biodeterior. Biodegradation 1992, 29 (3), 195-212.

8. Schultz, M. P.; Bendick, J. A.; Holm, E. R.; Hertel, W. M., Economic impact of biofouling on a naval surface ship. Biofouling 2011, 27 (1), 87-98.

9. Minchin, D.; Gollasch, S., Fouling and Ships' Hulls: How Changing Circumstances and Spawning Events may Result in the Spread of Exotic Species. Biofouling 2003, 19 (sup1), 111122.

10. Ruane, N. M.; Rodger, H.; Mitchell, S.; Doyle, T.; Baxter, E.; Fringuelli, E. GILPAT: An Investigation into Gill Pathologies in Marine Reared Finfish; Marine Institute: 2013.

11. Carl, C.; Guenther, J.; Sunde, L. M., Larval release and attachment modes of the hydroid Ectopleura larynx on aquaculture nets in Norway. Aquacult. Res. 2011, 42 (7), 1056-1060.

12. Baxter, E. J.; Sturt, M. M.; Ruane, N. M.; Doyle, T. K.; McAllen, R.; Rodger, H. D., Biofouling of the hydroid Ectopleura larynx on aquaculture nets in Ireland: Implications for finfish health. Fish Vet. J. 2012, 13, 17-29.

13. Magin, C. M.; Cooper, S. P.; Brennan, A. B., Non-toxic antifouling strategies. Materials Today 2010, 13 (4), 36-44.

14. Senda, T.; Miyata, O.; Kihara, T.; Yamada, Y., Inspection Method for the Identification of TBT-containing Antifouling Paints. Biofouling 2003, 19 (sup1), 231-237.

15. Dobretsov, S.; Teplitski, M.; Paul, V., Mini-review: quorum sensing in the marine environment and its relationship to biofouling. Biofouling 2009, 25 (5), 413-427.

16. Bixler, G. D.; Bhushan, B., Biofouling: lessons from nature. Philos. Trans. R. Soc. London, A 2012, 370 (1967), 2381-2417.

17. Schumacher, J. F.; Aldred, N.; Callow, M. E.; Finlay, J. A.; Callow, J. A.; Clare, A. S.; Brennan, A. B., Species-specific engineered antifouling topographies: correlations between the settlement of algal zoospores and barnacle cyprids. Biofouling 2007, 23 (5), 307-317. 
18. Banerjee, I.; Pangule, R. C.; Kane, R. S., Antifouling Coatings: Recent Developments in the Design of Surfaces That Prevent Fouling by Proteins, Bacteria, and Marine Organisms. Adv. Mater. (Weinheim, Ger.) 2011, 23 (6), 690-718.

19. Lejars, M.; Margaillan, A.; Bressy, C., Fouling Release Coatings: A Nontoxic Alternative to Biocidal Antifouling Coatings. Chem. Rev. 2012, 112 (8), 4347-4390.

20. Rosenhahn, A.; Schilp, S.; Kreuzer, H. J.; Grunze, M., The role of "inert" surface chemistry in marine biofouling prevention. Phys. Chem. Chem. Phys. 2010, 12 (17), 4275-4286.

21. Kirschner, C. M.; Brennan, A. B., Bio-Inspired Antifouling Strategies. Annu. Rev. Mater. Res. 2012, 42 (1), 211-229.

22. Aldred, N.; Li, G.; Gao, Y.; Clare, A. S.; Jiang, S., Modulation of barnacle (Balanus amphitrite Darwin) cyprid settlement behavior by sulfobetaine and carboxybetaine methacrylate polymer coatings. Biofouling 2010, 26 (6), 673-683.

23. Perrino, C.; Lee, S.; Choi, S. W.; Maruyama, A.; Spencer, N. D., A Biomimetic Alternative to Poly(ethylene glycol) as an Antifouling Coating: Resistance to Nonspecific Protein Adsorption of Poly(I-lysine)-graft-dextran. Langmuir 2008, 24 (16), 8850-8856.

24. Ostuni, E.; Chapman, R. G.; Holmlin, R. E.; Takayama, S.; Whitesides, G. M., A Survey of Structure-Property Relationships of Surfaces that Resist the Adsorption of Protein. Langmuir 2001, 17 (18), 5605-5620.

25. Ederth, T.; Ekblad, T.; Pettitt, M. E.; Conlan, S. L.; Du, C.-X.; Callow, M. E.; Callow, J. A.; Mutton, R.; Clare, A. S.; D'Souza, F.; Donnelly, G.; Bruin, A.; Willemsen, P. R.; Su, X. J.; Wang, S.; Zhao, Q.; Hederos, M.; Konradsson, P.; Liedberg, B., Resistance of GalactosideTerminated Alkanethiol Self-Assembled Monolayers to Marine Fouling Organisms. ACS Appl. Mater. Interfaces 2011, 3 (10), 3890-3901.

26. Luk, Y.-Y.; Kato, M.; Mrksich, M., Self-Assembled Monolayers of Alkanethiolates Presenting Mannitol Groups Are Inert to Protein Adsorption and Cell Attachment. Langmuir 2000, 16 (24), 9604-9608.

27. Hederos, M.; Konradsson, P.; Liedberg, B., Synthesis and Self-Assembly of GalactoseTerminated Alkanethiols and Their Ability to Resist Proteins. Langmuir 2005, 21 (7), 29712980.

28. Cao, X.; Pettit, M. E.; Conlan, S. L.; Wagner, W.; Ho, A. D.; Clare, A. S.; Callow, J. A.; Callow, M. E.; Grunze, M.; Rosenhahn, A., Resistance of Polysaccharide Coatings to Proteins, Hematopoietic Cells, and Marine Organisms. Biomacromolecules 2009, 10 (4), 907-915.

29. Nurioglu, A. G.; Esteves, A. C. C.; de With, G., Non-toxic, non-biocide-release antifouling coatings based on molecular structure design for marine applications. J. Mater. Chem. $B$ 2015, 3 (32), 6547-6570. 
30. Jayasundara, D. R.; Duff, T.; Angione, M. D.; Bourke, J.; Murphy, D. M.; Scanlan, E. M.; Colavita, P. E., Carbohydrate Coatings via Aryldiazonium Chemistry for Surface Biomimicry. Chem. Mater. 2013, 25 (20), 4122-4128.

31. Zen, F.; Angione, M. D.; Behan, J. A.; Cullen, R. J.; Duff, T.; Vasconcelos, J. M.; Scanlan, E. M.; Colavita, P. E., Modulation of Protein Fouling and Interfacial Properties at Carbon Surfaces via Immobilization of Glycans Using Aryldiazonium Chemistry. Sci. Rep. 2016, 6, 24840.

32. Esteban-Tejeda, L.; Duff, T.; Ciapetti, G.; Daniela Angione, M.; Myles, A.; Vasconcelos, J. M.; Scanlan, E. M.; Colavita, P. E., Stable hydrophilic poly(dimethylsiloxane) via glycan surface functionalization. Polymer 2016, 106, 1-7.

33. Angione, M. D.; Duff, T.; Bell, A. P.; Stamatin, S. N.; Fay, C.; Diamond, D.; Scanlan, E. M.; Colavita, P. E., Enhanced Antifouling Properties of Carbohydrate Coated Poly(ether sulfone) Membranes. ACS Appl. Mater. Interfaces 2015, 7 (31), 17238-17246.

34. Mandrino, D.; Godec, M.; Torkar, M.; Jenko, M., Study of oxide protective layers on stainless steel by AES, EDS and XPS. Surf. Interface Anal. 2008, 40 (3-4), 285-289.

35. Hassel, M.; Hemmerich, I.; Kuhlenbeck, H.; Freund, H.-J., High Resolution XPS Study of a Thin $\mathrm{Cr}_{2} \mathrm{O}_{3}(111)$ Film Grown on $\mathrm{Cr}(110)$. Surf. Sci. Spectra 1996, 4 (3), 246-252.

36. Beeskow, T.; Kroner, K. H.; Anspach, F. B., Nylon-Based Affinity Membranes: Impacts of Surface Modification on Protein Adsorption. J. Colloid Interface Sci. 1997, 196 (2), 278-291.

37. Railkin, A. I., Marine Biofouling: Colonization Processes and Defenses. CRC Press: 2003.

38. Tanane, O.; Abboud, Y.; Aitenneite, H.; El Bouari, A., Corrosion inhibition of the 316L stainless steel in sodium hypochlorite media by sodium silicate. J. Mater. Environ. Sci. 2016, $7(1), 131-138$.

39. Lins, V. d. F. C.; Gonçalves, G. A. d. S.; Leão, T. P.; Soares, R. B.; Costa, C. G. F.; Viana, A. K. d. N., Corrosion resistance of AISI 304 and 444 stainless steel pipes in sanitizing solutions of clean-in-place process. Mat. Res. 2016, 19, 333-338.

40. Pierozynski, B.; Kowalski, I., The Influence of Hypochlorite-Based Disinfectants on the Pitting Corrosion of Welded Joints of 316L Stainless Steel Dairy Reactor. Int. J. Electrochem. Sci. 2011, 6, 3913-3921.

41. Cairns, T. L.; Foster, H. D.; Larchar, A. W.; Schneider, A. K.; Schreiber, R. S., Preparation and Properties of N-Methylol, N-Alkoxymethyl and N-Alkylthiomethyl Polyamides. J. Am. Chem. Soc. 1949, 71 (2), 651-655.

42. Lin, J.; Winkelman, C.; Worley, S. D.; Broughton, R. M.; Williams, J. F., Antimicrobial treatment of nylon. J. Appl. Polym. Sci. 2001, 81 (4), 943-947. 
43. Tang, S.; Lu, N.; Myung, S.-W.; Choi, H.-S., Enhancement of adhesion strength between two AISI $316 \mathrm{~L}$ stainless steel plates through atmospheric pressure plasma treatment. Surf. Coat. Technol. 2006, 200 (18-19), 5220-5228.

44. Maupin, K. A.; Liden, D.; Haab, B. B., The fine specificity of mannose-binding and galactose-binding lectins revealed using outlier motif analysis of glycan array data. Glycobiology 2012, 22 (1), 160-169.

45. Hryniewicz, T.; Rokosz, K.; Rokicki, R., Electrochemical and XPS studies of AISI 316L stainless steel after electropolishing in a magnetic field. Corros. Sci. 2008, 50 (9), 2676-2681.

46. Williams, D. F.; Kellar, E. J. C.; Jesson, D. A.; Watts, J. F., Surface analysis of 316 stainless steel treated with cold atmospheric plasma. Appl. Surf. Sci. 2017, 403 (Supplement C), 240247.

47. Saulou, C.; Despax, B.; Raynaud, P.; Zanna, S.; Marcus, P.; Mercier-Bonin, M., PlasmaMediated Modification of Austenitic Stainless Steel: Application to the Prevention of Yeast Adhesion. Plasma Processes Polym. 2009, 6 (12), 813-824.

48. Dilks, A.; Kay, E., Plasma polymerization of ethylene and the series of fluoroethylenes: plasma effluent mass spectrometry and ESCA studies. Macromolecules 1981, 14 (3), 855 862.

49. Ferraria, A. M.; Lopes da Silva, J. D.; Botelho do Rego, A. M., XPS studies of directly fluorinated HDPE: problems and solutions. Polymer 2003, 44 (23), 7241-7249.

50. Golub, M. A.; Wydeven, T.; Johnson, A. L., Similarity of Plasma-Polymerized Tetrafluoroethylene and Fluoropolymer Films Deposited by rf Sputtering of Poly(tetrafluoroethylene). Langmuir 1998, 14 (8), 2217-2220.

51. Gu, X.; Nemoto, T.; Teramoto, A.; Ito, T.; Ohmi, T., Effect of Additives in Organic Acid Solutions for Post-CMP Cleaning on Polymer Low-k Fluorocarbon. J. Electrochem. Soc. 2009, 156 (6), H409-H415.

52. Powell, C. J.; Jablonski, A., NIST Electron Inelastic-Mean-Free-Path Database, Version 1.2. NIST Standard Reference Database, National Institute of Standards and Technology: Gaithersburgh, MD, 2010; Vol. 71.

53. Nichols, B. M.; Butler, J. E.; Russell, J. N.; Hamers, R. J., Photochemical Functionalization of Hydrogen-Terminated Diamond Surfaces: A Structural and Mechanistic Study. J. Phys. Chem. B 2005, 109 (44), 20938-20947.

54. Hinz, H. J.; Kuttenreich, H.; Meyer, R.; Renner, M.; Fruend, R.; Koynova, R.; Boyanov, A.; Tenchov, B., Stereochemistry and size of sugar head groups determine structure and phase behavior of glycolipid membranes: densitometric, calorimetric, and $\mathrm{x}$-ray studies.

Biochemistry 1991, 30 (21), 5125-5138.

55. Socrates, G., Infrared and Raman Characteristic Group Frequencies: Tables and Charts. John Wiley \& Sons: 2001. 
56. García Martínez, A.; de la Moya Cerero, S.; Osío Barcina, J.; Moreno Jiménez, F.; Lora Maroto, B., The Mechanism of Hydrolysis of Aryldiazonium lons Revisited: Marcus Theory vs. Canonical Variational Transition State Theory. Eur. J. Org. Chem. 2013, 2013 (27), 60986107.

57. Hinge, M.; Gonçalves, E. S.; Pedersen, S. U.; Daasbjerg, K., On the electrografting of stainless steel from para-substituted aryldiazonium salts and the thermal stability of the grafted layer. Surf. Coat. Technol. 2010, 205 (3), 820-827.

58. Hinge, M.; Ceccato, M.; Kingshott, P.; Besenbacher, F.; Pedersen, S. U.; Daasbjerg, K., Electrochemical modification of chromium surfaces using 4-nitro- and 4fluorobenzenediazonium salts. New J. Chem. 2009, 33 (12), 2405-2408.

59. Le, X. T.; Zeb, G.; Jégou, P.; Berthelot, T., Electrografting of stainless steel by the diazonium salt of 4-aminobenzylphosphonic acid. Electrochim. Acta 2012, 71, 66-72.

60. Small, L. J.; Hibbs, M. R.; Wheeler, D. R., Spontaneous Aryldiazonium Film Formation on 440C Stainless Steel in Nonaqueous Environments. Langmuir 2014, 30 (47), 14212-14218.

61. Adenier, A.; Barré, N.; Cabet-Deliry, E.; Chaussé, A.; Griveau, S.; Mercier, F.; Pinson, J.; Vautrin-UI, C., Study of the spontaneous formation of organic layers on carbon and metal surfaces from diazonium salts. Surf. Sci. 2006, 600 (21), 4801-4812.

62. Maurice, V.; Cadot, S.; Marcus, P., Hydroxylation of ultra-thin films of $\alpha-\mathrm{Cr}_{2} \mathrm{O}_{3}(0001)$ formed on $\mathrm{Cr}(110)$. Surf. Sci. 2001, 471 (1-3), 43-58.

63. Dechézelles, J.-F.; Griffete, N.; Dietsch, H.; Scheffold, F., A General Method to Label Metal Oxide Particles with Fluorescent Dyes Using Aryldiazonium Salts. Part. Part. Syst. Charact. 2013, 30 (7), 579-583.

64. Hurley, B. L.; McCreery, R. L., Covalent Bonding of Organic Molecules to Cu and Al Alloy 2024 T3 Surfaces via Diazonium Ion Reduction. J. Electrochem. Soc. 2004, 151 (5), B252B259.

65. Molino, P. J.; Wetherbee, R., The biology of biofouling diatoms and their role in the development of microbial slimes. Biofouling 2008, 24 (5), 365-379.

66. Karl, D. M., Total microbial biomass estimation derived from the measurement of particulate adenosine-5'-triphosphate. In Handbook of methods in aquatic microbial ecology, Kemp, P. F.; Cole, J. J.; Sherr, B. F.; Sherr, E. B., Eds. Lewis Publishers: Boca Raton :, 1993; pp 359-368.

67. Omidbakhsh, N.; Ahmadpour, F.; Kenny, N., How Reliable Are ATP Bioluminescence Meters in Assessing Decontamination of Environmental Surfaces in Healthcare Settings? . PLoS One 2014, 9 (6), e99951.

68. Hibbs, M. R.; Hernandez-Sanchez, B. A.; Daniels, J.; Stafslien, S. J., Polysulfone and polyacrylate-based zwitterionic coatings for the prevention and easy removal of marine biofouling. Biofouling 2015, 31 (7), 613-624. 

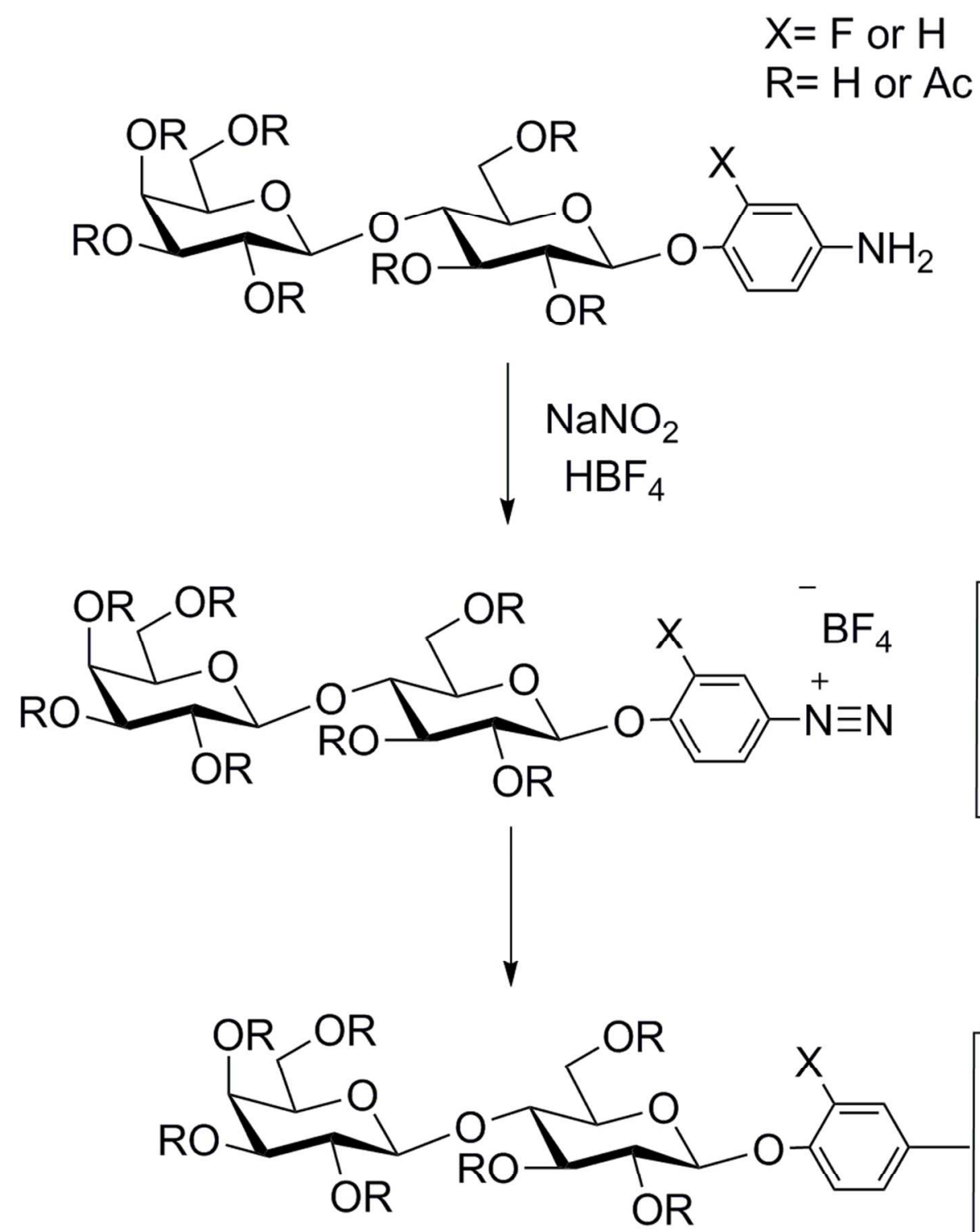<smiles>[X][R]OC</smiles><smiles>COC</smiles>

Scheme 1. 4-aminophenol- $\beta$-D-lactopyranose compounds used for all functionalized samples and reaction protocol used for diazotization and functionalization with aryldiazonium cations in situ.

$87 \times 106 \mathrm{~mm}(300 \times 300$ DPI) 

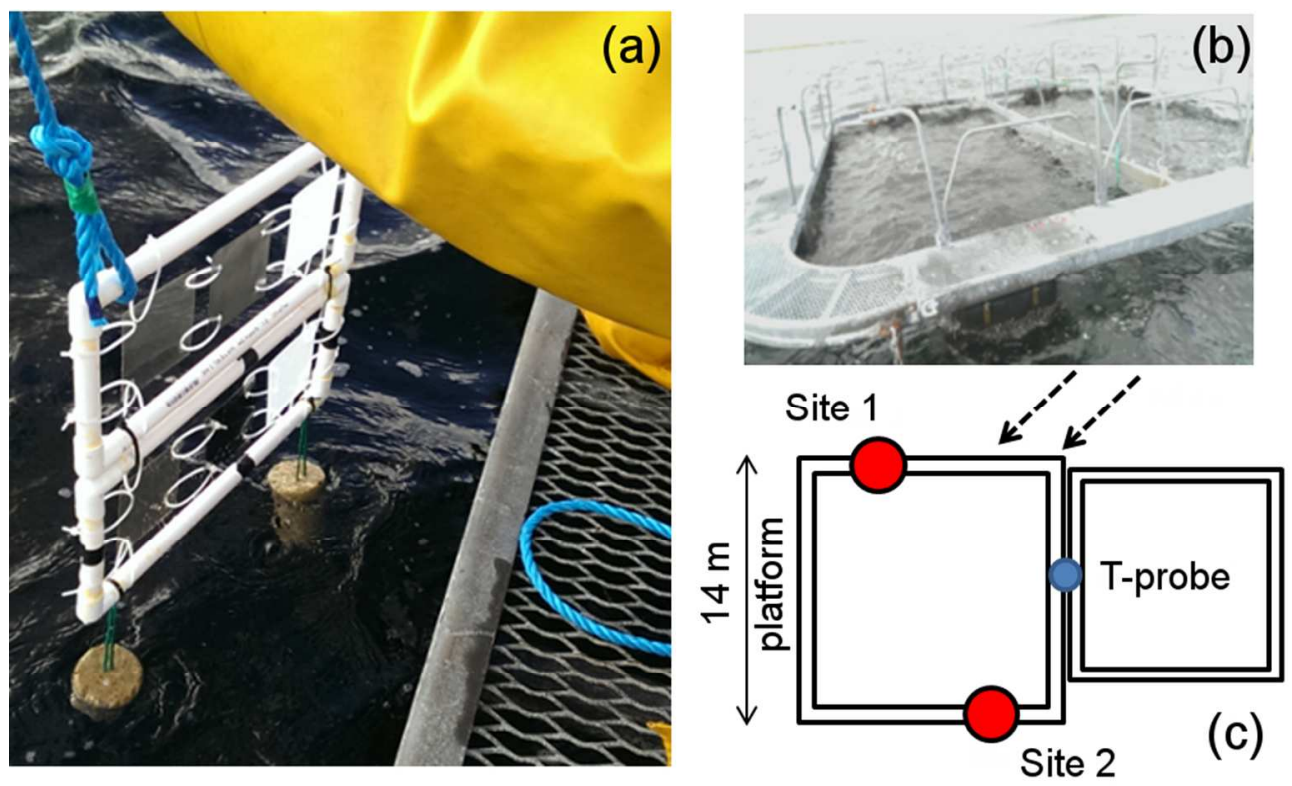

Figure 1. (a) Assembled frame with coupons, arranged from left to right, PES, SS316 and N6, immediately prior to immersion in sea water. (b) Salmon farm platform from which frames with coupons were suspended. (c) Scheme showing the two adjacent platforms and the location of frames at Site 1 and Site 2 relative to the tide (dashed arrows); a temperature probe measured surface water temperature at the position indicated in blue.

$86 \times 52 \mathrm{~mm}(300 \times 300$ DPI $)$ 

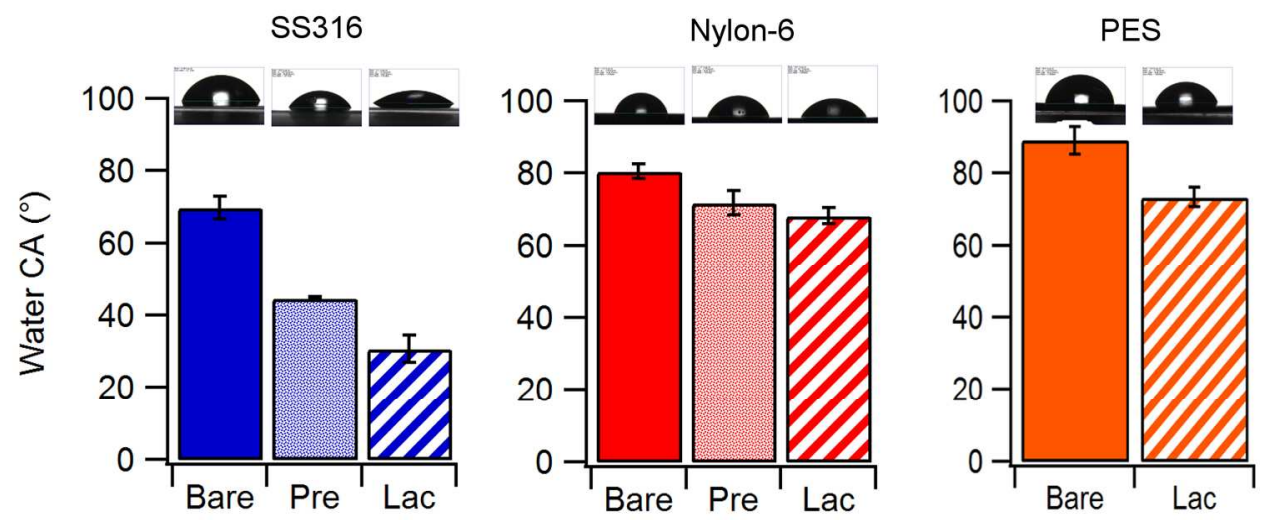

Figure 2. Water contact angle values obtained on bare, pre-treated (except for PES) and Lactose-modified (Lac) surfaces of SS316, Nylon-6 and PES. Samples were pre-activated in caustic bleach and formaldehyde solutions in the case of SS316 and nylon-6, respectively.

$159 \times 66 \mathrm{~mm}(300 \times 300$ DPI $)$ 
Figure 3. Fluorescence images obtained after lectin binding experiments using dye-conjugated PNA on Nylon- 6 and SS316 after pre-treatment and after aryldiazonium modification with lactosides (Lac). The images show that the emission intensity is higher on lactose-modified surfaces. Bar plots represent average emission intensities of Alexa-PNA on Nylon-6 (red bars) and of FITC-PNA on SS316 (green bars) obtained at pre-treated (Pre) and at lactose-modified coupons (Lac).

\section{$87 \times 53 \mathrm{~mm}(300 \times 300 \mathrm{DPI})$}


Figure 4. Fluorescence images obtained after protein adsorption experiments using dye-conjugated BSA on Nylon- 6 and SS316 after pre-treatment and after aryldiazonium modification with lactosides (Lac). The images show that the emission intensity is lower on lactose-modified surfaces. Bar plots represent average emission intensities of Alexa-BSA on Nylon-6 (red bars) and of FITC-BSA on SS316 (green bars) obtained at pre-treated (Pre) and at lactose-modified coupons (Lac).

$87 \times 52 \mathrm{~mm}(300 \times 300 \mathrm{DPI})$ 
(a)
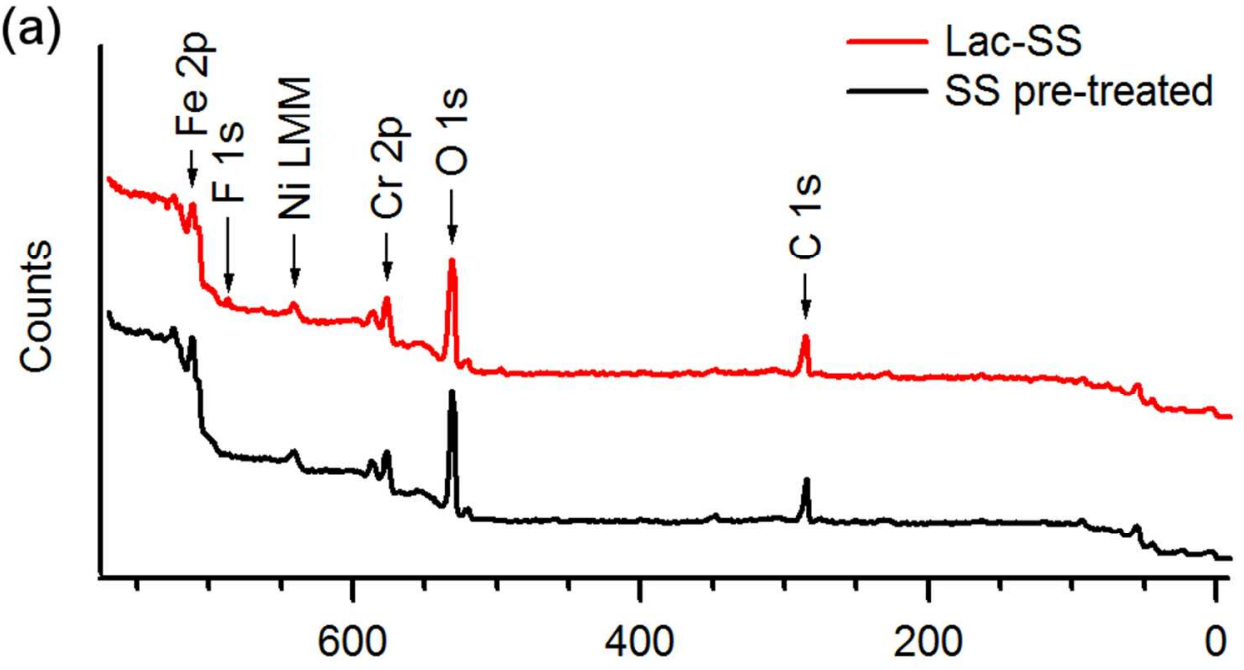

Binding Energy (eV)

(b)

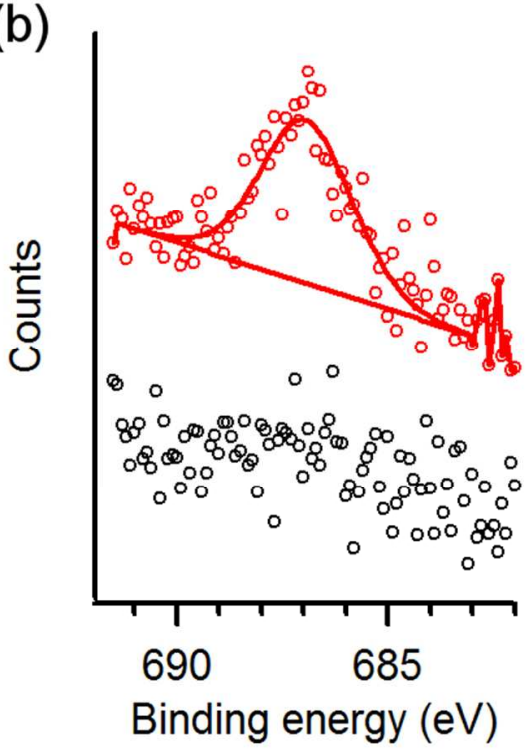

(c)

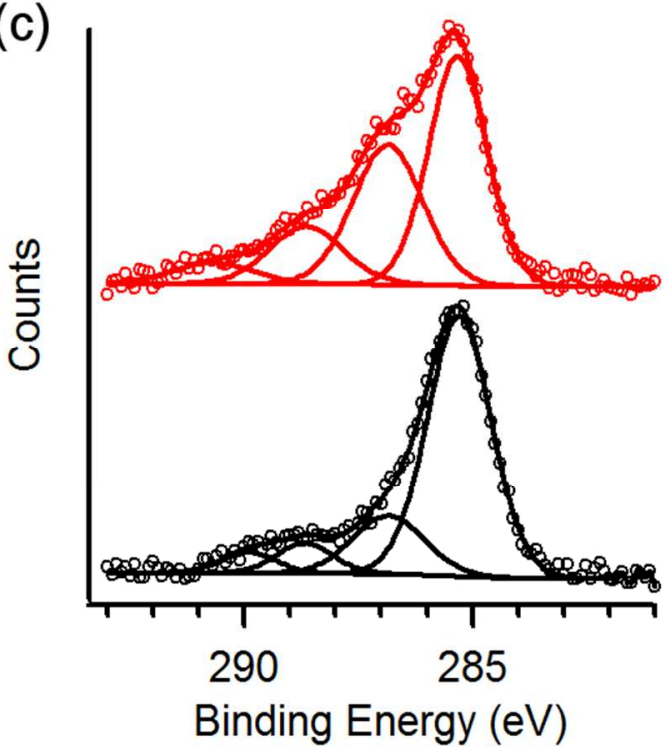

Figure 5. (a) Survey XPS spectra of SS316 after pre-treatment (black) and after modification with Fsubstituted aryl-lactoside (red). (b) F 1s and (c) C 1s high resolution spectra; these spectra show that upon reaction with aryldiazonium lactosides there appear peak contributions at $687 \mathrm{eV}$ and at 286-289 eV that can be attributed to F-atoms and $\mathrm{C}-\mathrm{O}$ groups, respectively.

$84 \times 99 \mathrm{~mm}(300 \times 300 \mathrm{DPI})$ 

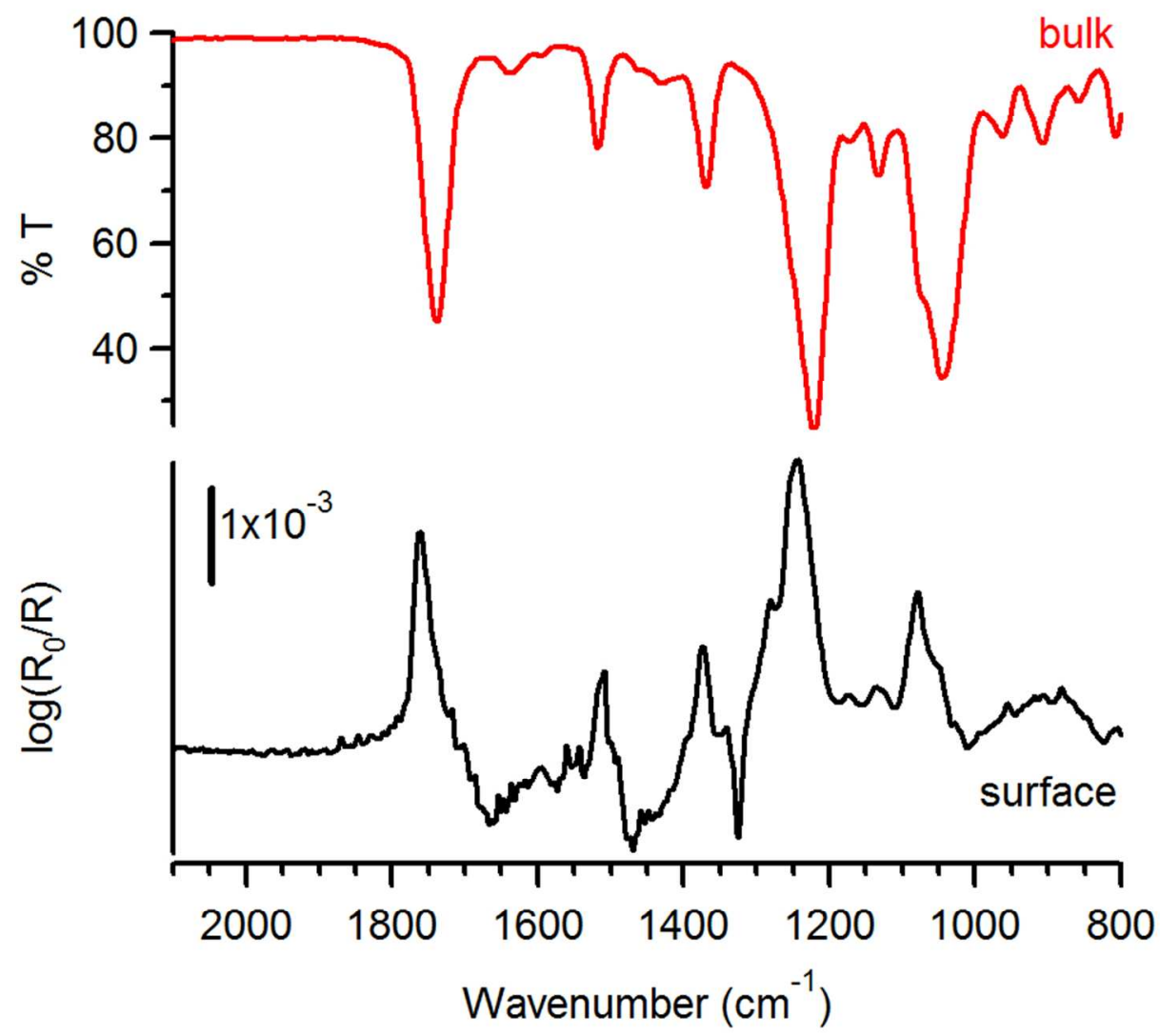

Figure 6. Infrared transmittance spectrum of a peracetylated aminophenol lactoside precursor (red, top) and IRRAS spectrum at $80^{\circ}$ incidence of the organic layer obtained after modification of a SS316 sample (black, bottom) with the same aryldiazonium precursor. The IRRAS spectrum displays the characteristic peaks of the precursor compound; peak assignments are discussed in the main text.

$81 \times 69 \mathrm{~mm}(300 \times 300 \mathrm{DPI})$ 


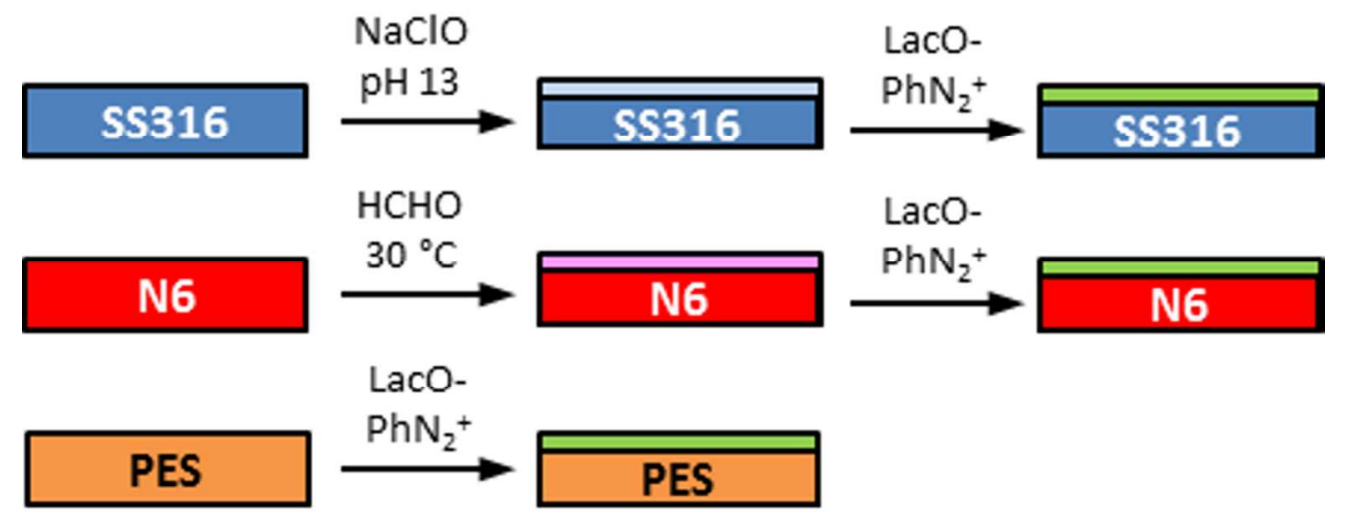

Scheme 2. Protocol used for the modification of SS316, N6 and PES. $80 \times 30 \mathrm{~mm}(300 \times 300 \mathrm{DPI})$ 

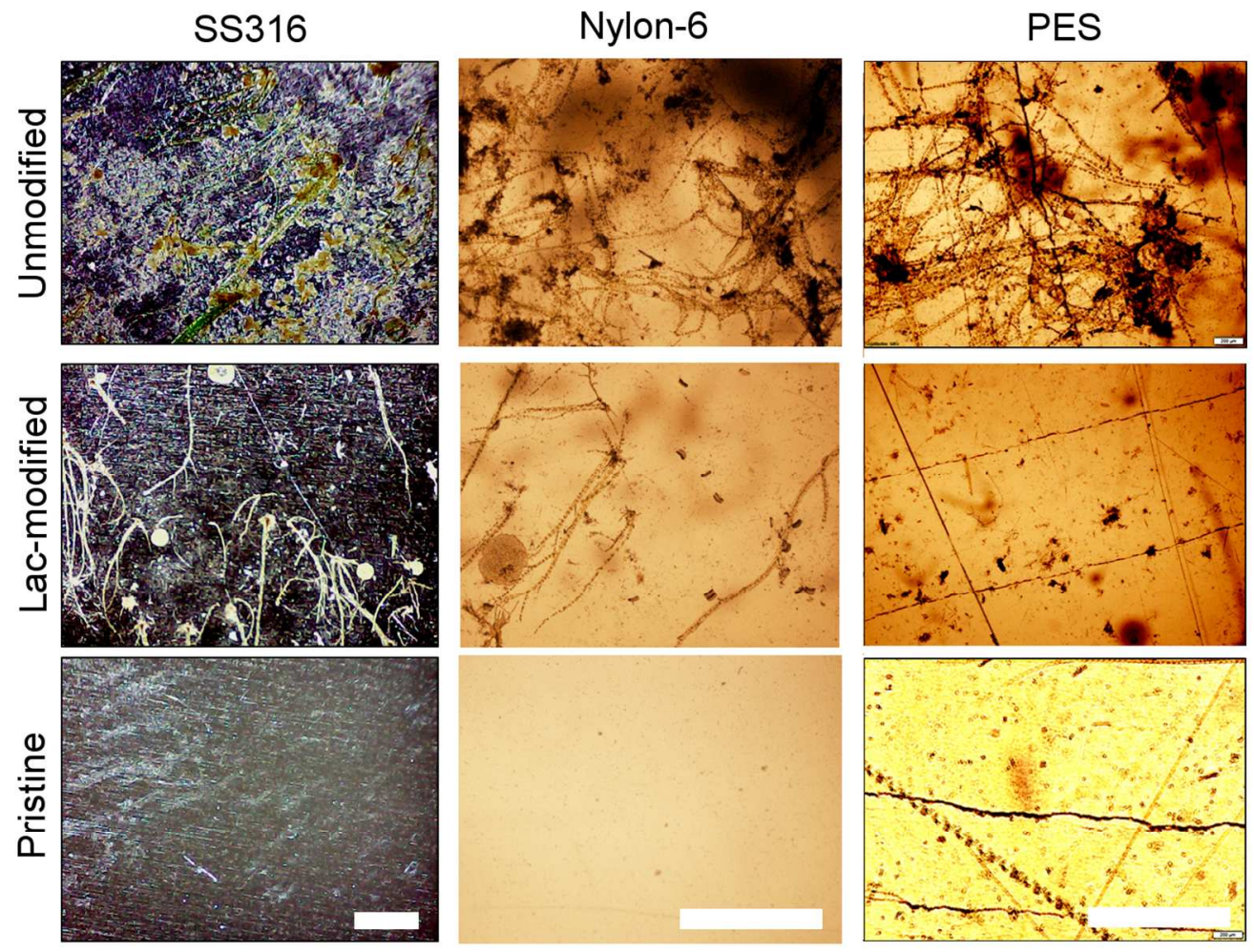

Figure 7. Optical microscope images of coupons of SS316, Nylon- and PES (scalebar $=1 \mathrm{~mm}$ ) extracted after 20 day immersion in coastal waters at site 1 (see Figure 1); samples were rinsed under the same conditions prior to imaging. The top row shows images of coupons that had not been coated with an aryldiazonium layer of glycosides; the middle row shows coupons that had been coated with a layer of lactosides prior to immersion; the bottom row shows samples as supplied by the vendor, without undergoing any immersion tests. All immersed samples display biomass accumulation however the density of adhered organic matter appears to be higher on unmodified when compared to lactoside-modified samples. 

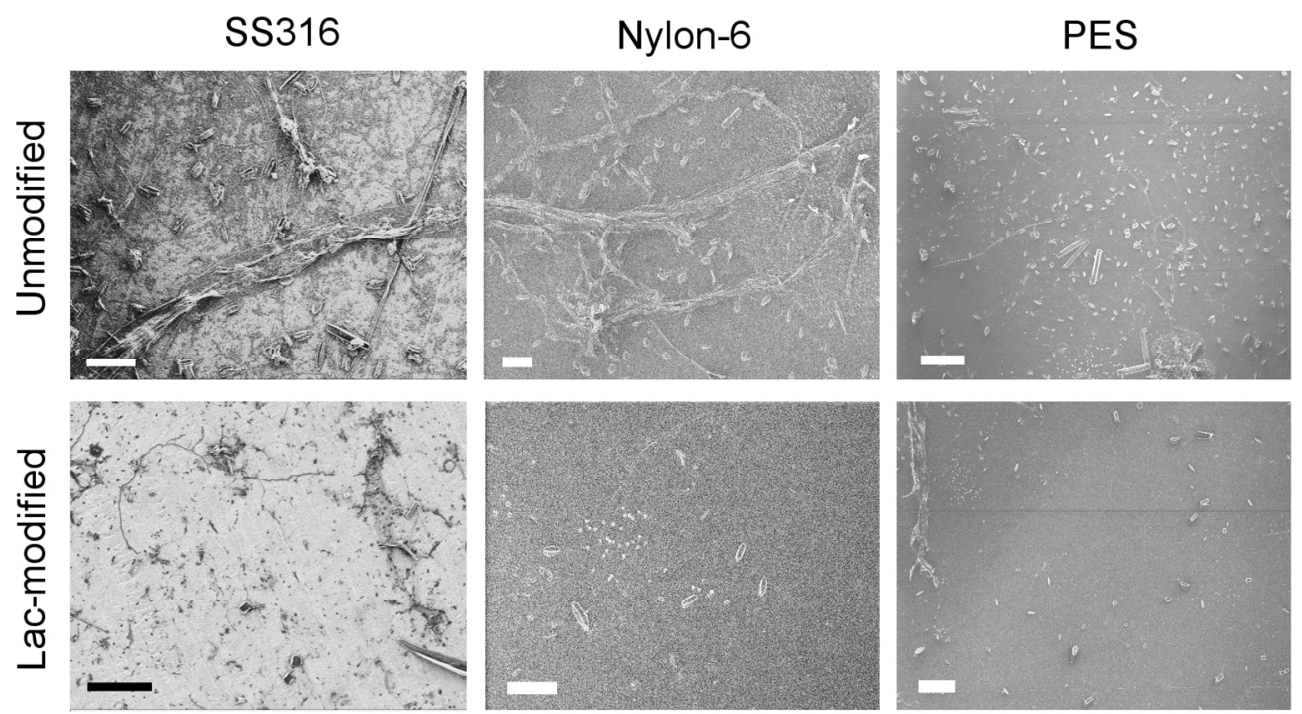

Figure 8. Microscopy images of coupons of SS316 (SEM, scalebar $=40 \mu \mathrm{m}$ ), Nylon-6 (HIM, scalebar $=40$ $\mu \mathrm{m})$ and PES (HIM, scalebar $=100 \mu \mathrm{m})$. The figures show details of surfaces after 20 day immersion in coastal waters followed by rinsing under identical conditions prior to imaging. The top row shows images of coupons that had not been coated with an aryldiazonium layer of glycosides; the bottom row shows coupons that had been coated with a layer of lactosides prior to immersion.

$$
141 \times 78 \mathrm{~mm}(300 \times 300 \mathrm{DPI})
$$



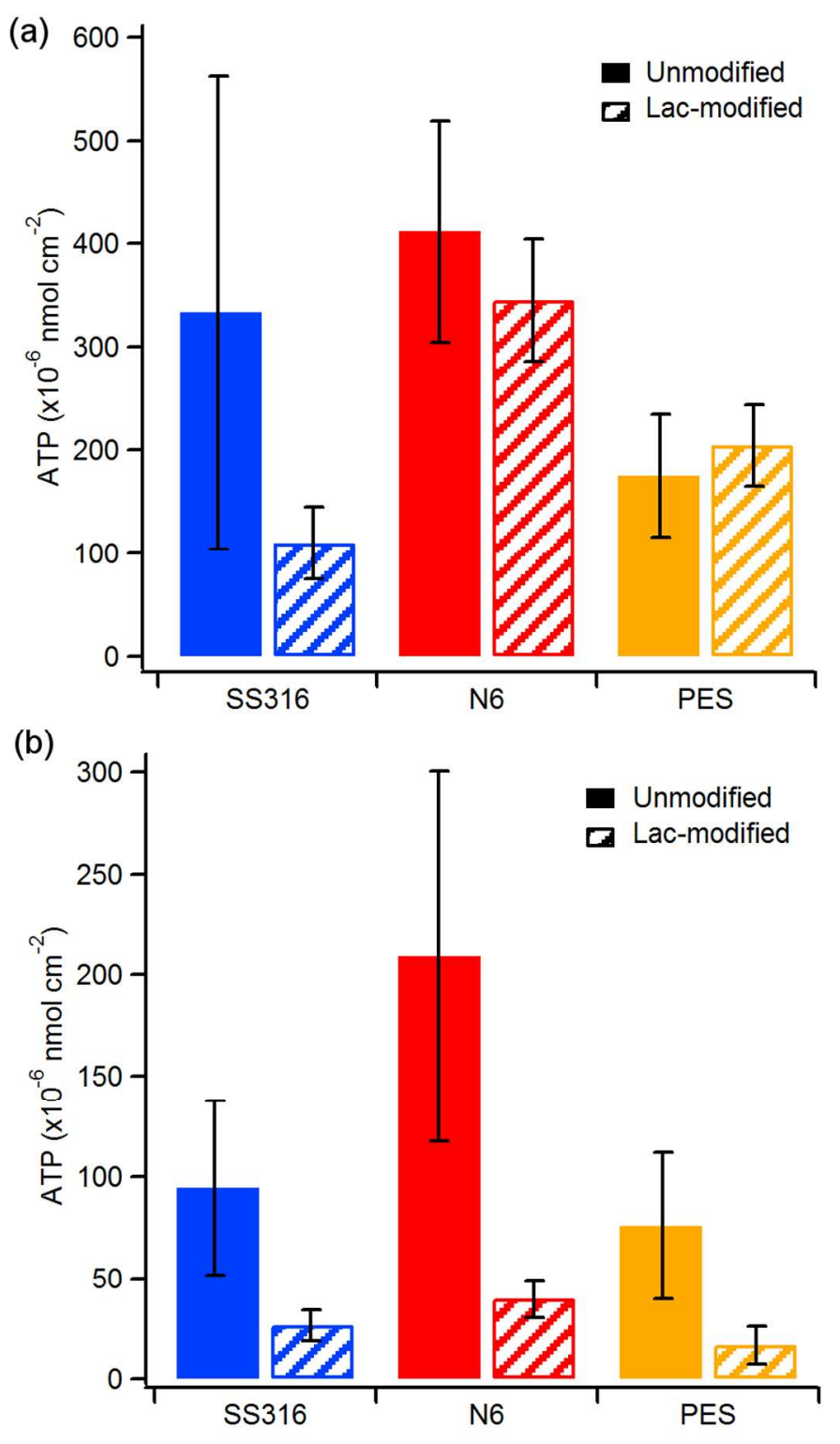

Figure 9. Average ATP released per unit area from unmodified (solid) and lactose-modified (striped) SS316, nylon- 6 and PES coupons after 20 day immersion tests in coastal waters prior to any rinsing (a) and after controlled rinsing (b). Error bars indicate $90 \%$ C.I.

$84 \times 144 \mathrm{~mm}(300 \times 300$ DPI) 


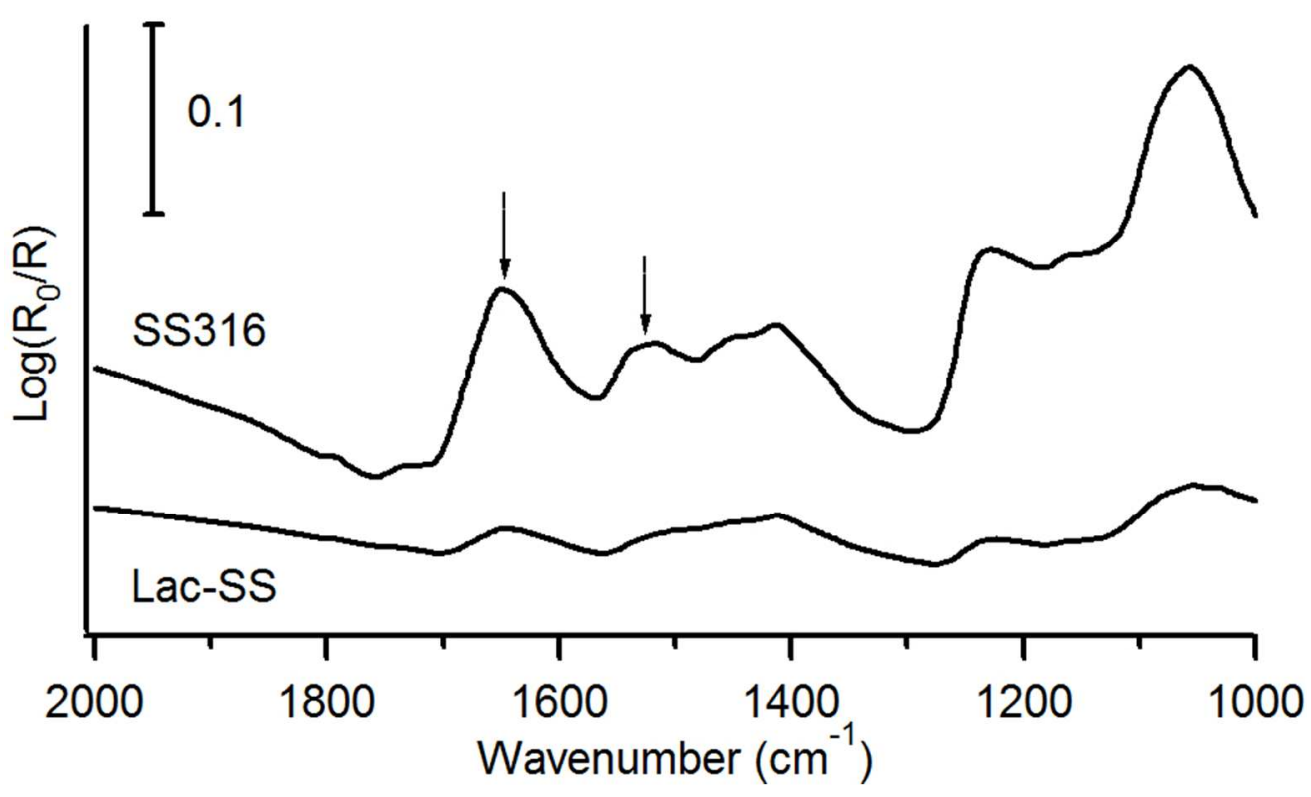

Figure 10. IRRAS spectra at $45^{\circ}$ incidence of SS316 unmodified sample and lactose-modified SS316 after 20 day immersion tests; this specific sample was located at site 2 however in all cases unmodified samples show more intense absorption peaks. Arrows indicate peaks at $1645 \mathrm{~cm}^{-1}$ and $1525 \mathrm{~cm}^{-1}$ corresponding to amide I and amide II modes, respectively.

$80 \times 50 \mathrm{~mm}(300 \times 300 \mathrm{DPI})$ 


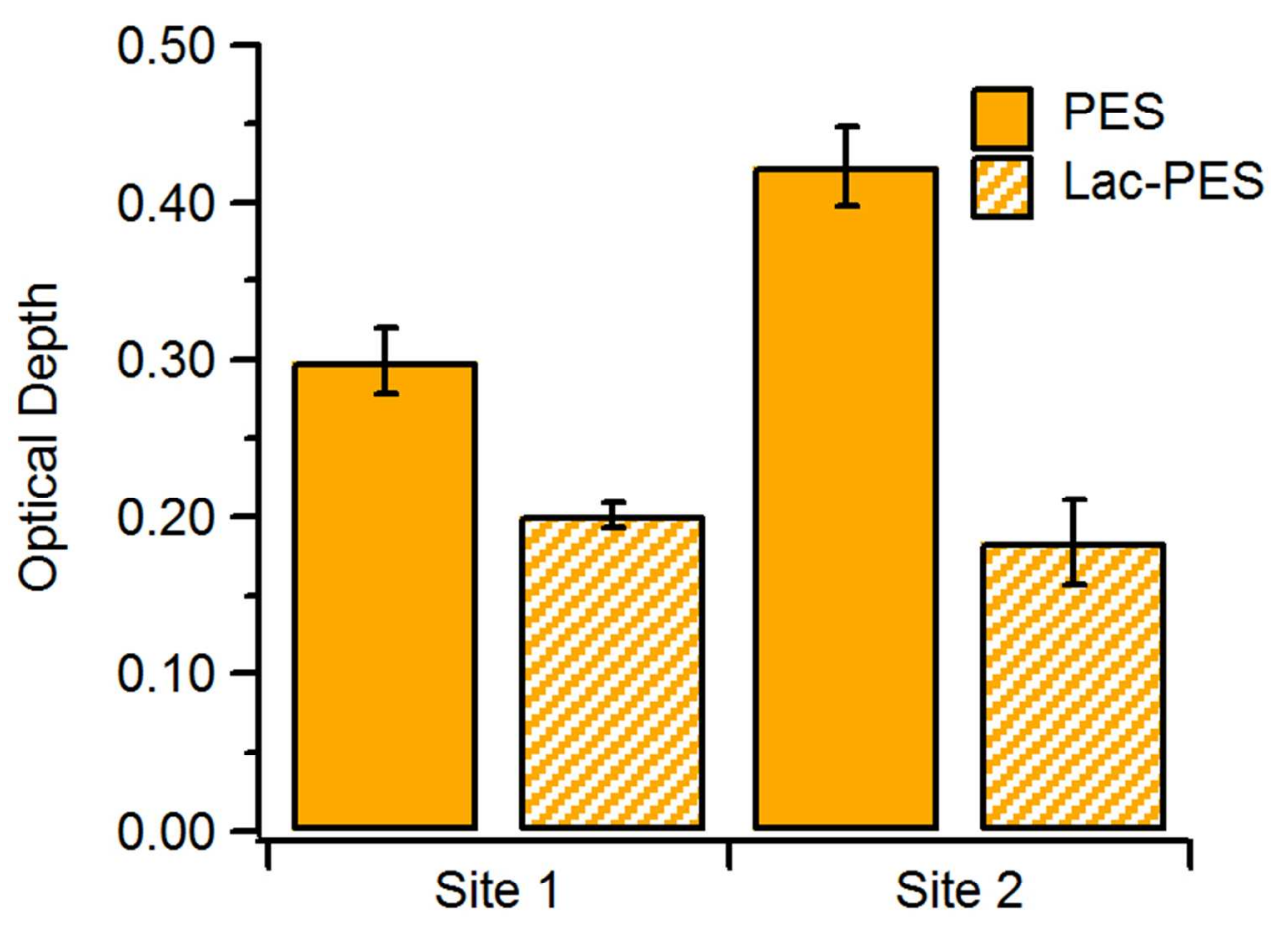

Figure 11. Optical depth of PES coupons at $600 \mathrm{~nm}$ measured after 20 day immersion test followed by controlled rinsing. Lac-modified samples are more transparent than unmodified ones.

$$
69 \times 55 \mathrm{~mm}(300 \times 300 \text { DPI })
$$




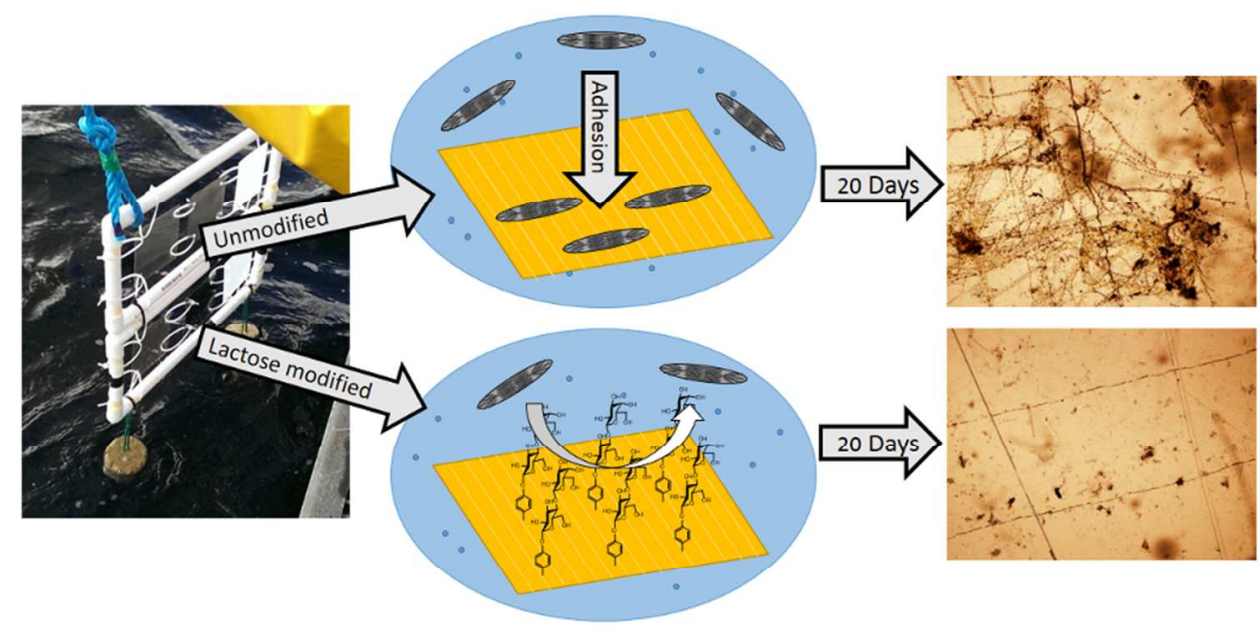

Ultra-thin saccharide layers offer a non-biocidal, sustainable fouling mitigation strategy. $84 \times 47 m m(300 \times 300$ DPI) 